\title{
Docetaxel and Lidocaine Co-Loaded (NLC-in-Hydrogel) Hybrid System Designed for the Treatment of Melanoma
}

\author{
Ludmilla David de Moura ${ }^{1}{ }^{\oplus}$, Lígia N. M. Ribeiro ${ }^{1,2}{ }^{\circledR}$, Fabíola V. de Carvalho ${ }^{1}{ }^{\circledR}$, Gustavo H. Rodrigues da Silva ${ }^{1}{ }^{\circledR}$, \\ Priscila C. Lima Fernandes ${ }^{1}$, Sérgio Q. Brunetto ${ }^{3}$, Celso D. Ramos ${ }^{3}$, Lício A. Velloso ${ }^{4}$, Daniele R. de Araújo ${ }^{5}$ \\ and Eneida de Paula ${ }^{1, *(1)}$
}

Citation: de Moura, L.D.; Ribeiro, L.N.M.; de Carvalho, F.V.; Rodrigues da Silva, G.H.; Lima Fernandes, P.C.; Brunetto, S.Q.; Ramos, C.D.; Velloso, L.A.; de Araújo, D.R.; de Paula, E. Docetaxel and Lidocaine Co-Loaded (NLC-in-Hydrogel) Hybrid System Designed for the Treatment of Melanoma. Pharmaceutics 2021, 13, 1552. https://doi.org/10.3390/ pharmaceutics13101552

Academic Editor: Pietro Matricardi

Received: 27 August 2021

Accepted: 19 September 2021

Published: 24 September 2021

Publisher's Note: MDPI stays neutral with regard to jurisdictional claims in published maps and institutional affiliations.

Copyright: (c) 2021 by the authors. Licensee MDPI, Basel, Switzerland. This article is an open access article distributed under the terms and conditions of the Creative Commons Attribution (CC BY) license (https:/ / creativecommons.org/licenses/by/ $4.0 /)$.
1 Department of Biochemistry and Tissue Biology, Institute of Biology, University of Campinas-UNICAMP, Campinas 13083-862, SP, Brazil; ludmilladavidm@gmail.com (L.D.d.M.); nuneslica@gmail.com (L.N.M.R.); fabiolavieiracarvalho@hotmail.com (F.V.d.C.); gustavohrs@gmail.com (G.H.R.d.S.); priscila_biologa@yahoo.com.br (P.C.L.F.)

2 Institute of Biotechnology, Federal University of Uberlândia-UFU, Uberlândia 38405-319, MG, Brazil

3 Radiology Department, University of Campinas-UNICAMP, Campinas 13083-887, SP, Brazil; brunetto@unicamp.br (S.Q.B.); cdramos@unicamp.br (C.D.R.)

4 Clinical Medicine Department, School of Medicine Science, University of Campinas-UNICAMP, Campinas 13083-887, SP, Brazil; lsincel@unicamp.br

5 Human and Natural Science Center, ABC Federal University—UFABC, Santo André 09210-580, SP, Brazil; daniele.araujo@ufabc.edu.br

* Correspondence: depaula@unicamp.br

Abstract: Melanoma is the most aggressive skin carcinoma and nanotechnology can bring new options for its pharmacological treatment. Nanostructured lipid carriers (NLC) are ideal drugdelivery carriers for hydrophobic drugs, such as the antineoplastic docetaxel (DTX), and hybrid (NLC-in-hydrogel) systems are suitable for topical application. This work describes a formulation of NLC $_{\text {DTX }}$ in xanthan-chitosan hydrogel containing lidocaine (LDC) with anticancer and analgesia effects. The optimized nanoparticles encapsulated 96\% DTX and rheological analysis revealed inherent viscoelastic properties of the hydrogel. In vitro assays over murine fibroblasts (NIH/3T3) and melanoma cells (B16-F10), human keratinocytes (HaCaT) and melanoma cells (SK-MEL-103) showed reduction of docetaxel cytotoxicity after encapsulation in NLC $_{\mathrm{DTX}}$ and HGel-NLC $\mathrm{DTX}_{\text {. }}$ Addition of LDC to the hybrid system (HGel-NLC $\mathrm{DTX}_{\mathrm{DDC}}$ ) increased cell death in tumor and normal cells. In vivo tests on C57BL/6J mice with B16-F10-induced melanoma indicated that LDC, NLC $_{\text {DTX }}$, HGel-NLC DTX $_{\text {-LDC and NLC }}$ DTX + HGel-LDC significantly inhibited tumor growth while microPET/SPECT/CT data suggest better prognosis with the hybrid treatment. No adverse effects were observed in cell survival, weight/feed-consumption or serum biochemical markers (ALT, AST, creatinine, urea) of animals treated with $\mathrm{NLC}_{\mathrm{DTX}}$ or the hybrid system. These results confirm the adjuvant antitumor effect of lidocaine and endorse HGel-NLC DTX $_{\text {-LDC }}$ as a promising formulation for the topical treatment of melanoma.

Keywords: nanostructured lipid carriers; hydrogel; lidocaine; docetaxel; melanoma

\section{Introduction}

Cutaneous melanoma is the most aggressive form of skin cancer due to the high rate $(50 \%)$ of brain metastasis [1]. Although melanoma corresponds to only $2 \%$ of the registered cases of skin cancer, it is the cause of $80 \%$ of patient deaths [2]. The standard treatment of melanoma is the chemotherapy associated with surgical excision. However, melanoma's high recurrence rate and low response and resistance to drug therapy $[3,4]$ compel advances in treatments to improve patients' survival. In this sense, nanotechnology developments can provide the sustained release of drugs, increasing their therapeutic efficiency and decreasing systemic toxicity [5]. 
Nanostructured lipid carriers (NLC) are drug delivery systems composed of a matrix of solid and liquid lipids stabilized by a surfactant [6,7]. In comparison to other lipid-based carriers such as liposomes and solid lipid nanoparticles, NLC have higher encapsulation efficiency and prolonged release times [8,9] for nonpolar drugs. Hydrophobic antineoplastic agents such as the semi-synthetic taxane docetaxel (DTX) are suitable candidates to be loaded in NLC. DTX is a cytostatic drug for the control of tumor tissue growth [10] widely used against breast, ovarian, prostate, non-small-cell lung cancer, melanoma, gastric adenocarcinoma and other cancer types [11]. DTX reversibly binds and promotes transitory microtubule stabilization, leading to cell cycle arrest [11].

Biopolymer-based hydrogels are also used as drug delivery carriers [12]. Alginate, xanthan, gelatin and chitosan are biocompatible, abundant, cheap [13-15] and bioadhesive biopolymers that promote fixation to the area of interest, allowing a more efficient drug release/biological activity in relation to ointments and creams $[15,16]$. Furthermore, hydrogels can be associated with nanoparticles to form nanohybrid systems [16-18] as shown in here for $\mathrm{NLC}_{\mathrm{DTX}}$ in a xanthan-chitosan hydrogel containing lidocaine (HGel-NLC $\mathrm{DTX}_{\mathrm{DT}}$-LDC).

Recently, several works have described the adjuvant anticancer action of local anesthetics such as LDC [19,20], bupivacaine [21-24] and ropivacaine [25]. LDC can suppress cancer cell growth (in vitro and in vivo) through several mechanisms: regulation of epigenetic changes, promotion of pro-apoptotic pathways and regulation of $\mathrm{ABC}$ transporters, also preventing metastasis and angiogenesis. However, these effects differ according to the cell line used and LDC shows time and dose-dependent cytotoxicity [26,27]. Therefore, a deep evaluation of the use of local anesthetics as anticancer agents is compelling, since their mechanisms of action may open new options for the cancer treatment $[20,28,29]$.

In this work, a hybrid NLC-hydrogel is proposed as an innovative formulation for the treatment of melanoma. The hybrid hydrogel formulation uploads $2 \%(w / v)$ LDC incorporated in a (xanthan-chitosan) biopolymer matrix plus $0.5 \%(w / v)$ DTX incorporated in NLC. The formulation was structurally characterized, and in vitro and in vivo biological assays confirmed increased drug bioavailability, equivalent tumor regression and lower systemic toxicity than free DTX. The hybrid hydrogel carrying LDC and DTX is then proposed as an outstanding therapeutic alternative for the treatment of cutaneous melanoma.

\section{Materials and Methods}

\subsection{Materials}

Docetaxel powder (DTX) and lidocaine hydrochloride (LDC) were donated by Cristália Prod. Quim. Farm. Ltd.a (Itapira, SP, Brazil). Docetaxel trihydrate $20 \mathrm{mg} \mathrm{mL}^{-1}$ (DTX T-HYD) was kindly provided by Blau Pharmaceutica S.A. (Cotia, SP, Brazil). 18F-fluorodeoxyglucose $\left({ }^{18} \mathrm{~F}-[\mathrm{FDG}]\right)$ was a gift from Cyclobras Ind. Com. Lab. Services Ltda (São Paulo, SP, Brazil). Pluronic F-68 (P68), Myristyl myristate (MM), Miglyol 812 ${ }^{\circledR}$ (MG), chitosan (CHT), xanthan (XAN), DMEM medium, fetal bovine serum and 3-(4,5-dimethylthiazol-2-yl)-2,5diphenyltetrazolium bromide (MTT) were supplied by Sigma-Aldrich (St. Louis, MO, USA). Deionized water (18 M $\Omega$ ) was obtained from an Elga USF Maxima ultra-pure water purifier. Phosphate-buffered saline (PBS), dimethyl sulfoxide and ultrapure water are from Laborclin (Pinhais, PR, Brazil), Vetec (São Paulo, SP, Brazil) and Barnstead ${ }^{\mathrm{TM}}$, Thermo Scientific (Thermo Scientific, Waltham, MA, USA), respectively. Murine fibroblasts (NIH3T3) and murine melanoma (B16-F10) cells were purchased from American type culture collection (ATCC, Manassas, VA, USA). Human melanoma (SK-MEL-103) and human keratinocytes $(\mathrm{HaCaT})$ cell line were purchased from Memorial Sloan Kettering cancer center (New York, NY, USA and CLS cell lines Service GmbH (Heidelberg, Germany), respectively. All other reagents were of analytical grade.

\subsection{NLC Preparation}

NLC formulations were prepared through the emulsification-ultrasonication method [30]. Briefly, an oily phase composed of MM $(65 \% w / w), \mathrm{MG}(35 \% w / w)$ and DTX $(1 \% w / w)$ was heated to $55^{\circ} \mathrm{C}$. An aqueous phase consisting of a P68 solution $(3 \% w / w)$ was heated to the 
same temperature and both phases were mixed under high-speed agitation $(10,000 \mathrm{rpm})$ for 3 min in an Ultra-Turrax homogenizer (IKA Werke, Staufen, Germany). The mixture was then sonicated for $30 \mathrm{~min}$ in a Vibracell tip sonicator (Sonics \& Mat. Inc., Danbury, CT, USA) at $60 \mathrm{~W}$ and $20 \mathrm{kHz}$, in alternating $30 \mathrm{~s}$ (on/off) cycles, to avoid sample overheating. After that, the samples were immediately cooled to room temperature in an ice bath. Control

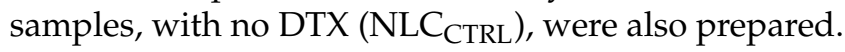

\subsection{NLC Characterization}

\subsubsection{Determination of Particle Size, Polydispersity and Zeta Potential}

The particle size (hydrodynamic diameter) and polydispersity index (PDI) were measured by dynamic light scattering (DLS) while Zeta potentials (ZP) were determined by electrophoretic mobility, using a Nano ZS90 analyzer (Malvern Panalytical, Worcestershire, UK). For the determination of nanoparticles concentration Nanotracking analysis was used, in a NS300 (NanoSight, Amesbury, UK) equipment. The samples were diluted 1000× (DLS) or $5000 \times(\mathrm{NTA})$ in deionized water and measured in triplicate, at $25^{\circ} \mathrm{C}$.

\subsubsection{DTX Quantification and Encapsulation in NLC}

The quantification of DTX was done using high performance liquid chromatography (HPLC), in Varian ProStar (PS 325 UV-visible detector and PS 210 pump) equipment equipped with Galaxie Workstation software (Walnut Creek, CA, USA). Briefly, a Gemini ${ }^{\circledR}$ $5 \mu \mathrm{m}, \mathrm{C} 18$ (Phenomenex ${ }^{\circledR}$, Torrance, MD, USA) column, with a mobile phase composed of $0.1 \% v / v$ phosphoric acid:methanol $(30: 70 \mathrm{v} / \mathrm{v})$ under a flow rate of $1 \mathrm{~mL} / \mathrm{min}$ was used. Absorbance was followed at $210 \mathrm{~nm}$ and the injection volume was $10 \mu \mathrm{L}$. The limits of detection and quantification of the analytical method were 3.0 and $9.0 \mu \mathrm{g} / \mathrm{mL}$, respectively.

Firstly, NLC suspensions were prepared by the homogenization-ultrasonication method. Then, the total amount of DTX in the formulations was determined by diluting the samples in the mobile phase $(n=3)$ followed by centrifugation in order to disrupt the nanoparticles and provide phase separation. The encapsulation efficiency (\%EE) of DTX in NLC formulations was determined by the ultrafiltration-centrifugation method [6]: $0.4 \mathrm{~mL}$ aliquots of the samples were transferred to a $10 \mathrm{kDa}$ pore filtration unit (Millex, Milipore, Burlington, MA USA) coupled to Eppendorf tubes and centrifuged for $20 \mathrm{~min}$ at $4100 \mathrm{~g}$; the filtered solution was collected and free DTX was quantified by HPLC. \%EE was calculated, according to [31]:

$$
\% \mathrm{EE}=\frac{\text { total drug }- \text { free drug }}{\text { total drug }} \times 100
$$

where total drug is the amount of DTX quantified in the NLC suspension and free drug represents the unloaded DTX fraction, determined in the filtrate.

Drug loading, expressing the amount of DTX encapsulated per gram of nanoparticle [32] was also calculated:

$$
\% \text { Drug loading }=\frac{\text { weight of encapsulated drug }(\mathrm{g})}{\text { weight of nanoparticles }(\mathrm{g})} \times 100
$$

\subsection{Hydrogel Preparation}

Chitosan was first solubilized in $0.1 \%$ acetic acid solution under constant magnetic stirring at $37{ }^{\circ} \mathrm{C}$ overnight, resulting in $3 \%$ chitosan solution $(w / v)$. Xanthan hydrogel $(5 \% w / v)$ was them prepared by dissolving the biopolymer in deionized water, under constant magnetic stirring, until complete homogenization. After that, biopolymer blends with different chitosan:xanthan mass ratios were prepared (Table S1). The selection of the most suitable biopolymer matrix considered the highest possible chitosan concentration, without inhomogeneities. A blend matrix containing 3\% (w/w) XAN and 1\% (w/w) CHT was chosen as the biopolymer component (XAN-CHT) of the hybrid hydrogel.

For the hybrid hydrogel preparation, nanoparticle suspensions containing or not $1 \%$ DTX $\left(\right.$ NLC $_{\text {DTX }}$ or NLC) were added to XAN-CHT matrix in a 1:1 $(w / v)$ ratio and mixed 
under high-speed agitation (1200 rpm) for $30 \mathrm{~s}$ in an Ultra-Turrax homogenizer (IKA Werke, Staufen, Germany). Then, 2\% LDC was dispersed in the XAN-CHT hydrogel samples and stirred for $2 \mathrm{~h}$ at room temperature. The prepared hydrogels (with final concentrations of $0.5 \%$ DTX and $2 \%$ LDC) were stabilized overnight at $4{ }^{\circ} \mathrm{C}$ and visually inspected before use.

The same method was used to prepare all kind of hydrogels: control-without NLC

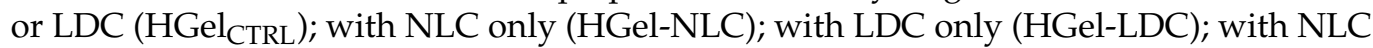
and DTX (HGel-NLC ${ }_{\text {DTX }}$ ) and with NLC $_{\text {DTX }}$ plus LDC (HGel-NLC DTX $_{\text {-LDC). }}$

\subsection{Hydrogel Characterization \\ 2.5.1. Rheological Analyses}

Oscillatory rheometry measurements of control and hybrid hydrogels were performed in Kinexus Lab equipment (Malvern Instruments, UK) by using a cone plate geometry (20 mm diameter) in the range of $0.1-10.0 \mathrm{~Hz}$, at constant shear stress $(1 \mathrm{~Pa})$ and temperature $\left(32.5^{\circ} \mathrm{C}\right.$, to simulate skin temperature application). Temperature scanning analyzes were also performed (from $10-50{ }^{\circ} \mathrm{C}$ ) at a defined frequency $\left(1 \mathrm{~Hz}\right.$ ), heating rate of $5^{\circ} \mathrm{C} / \mathrm{min}$ and $1 \mathrm{~Pa}$ shear stress. The storage module $\left(\mathrm{G}^{\prime}\right)$, loss module $\left(\mathrm{G}^{\prime \prime}\right)$ and dynamic viscosity $(\eta)$ were calculated using the Kinexus Rheometer rSpace software (NETZSCH Thermal Analysis, Wittelsbacherstraße, Germany).

\subsubsection{Field Emission Scanning (FE-SEM) and Cryo-Electron Microscopy (Cryo-EM)}

To elucidate the morphological properties of the hydrogels a Quanta Feg $250 \mathrm{FE}-$ SEM equipment (FEI Co., Hillsboro, OR, USA) was used. An aliquot of each hydrogel formulation was deposited on metal stubs previously mounted with a carbon ribbon. The sample was left to dry in a silica-containing desiccator for $24 \mathrm{~h}$ and covered with gold in a Bal-Tec SCD $050^{\circledR}$ metallizer (Balzers Union AG, Balzer, Liechtenstein) for further image analysis.

Cryo-electron microscopy (cryo-EM) allowed the structural analysis of the nanoparticles inside the hydrogel. For this, a 300 Mesh Holey Lacey Carbon grid was used, and the grids were submitted to a glow discharge procedure (Pelco EasiGlow discharge system, Ted Pella ${ }^{\circledR}$, Redding, CA, USA) of $20 \mathrm{~mA}$ for $10 \mathrm{~s}$, to make them more hydrophilic. Then, grids were inserted in a Mark IV Vitrobot ${ }^{\circledR}$ (Thermo Scientific, Waltham, MA, USA) where they received $3 \mu \mathrm{L}$ of sample, left to fix for $20 \mathrm{~s}$. Subsequently, an automatic transfer (3 s) was performed to dry the excess sample with a negative transfer force (blot force $=-5$ ). Finally, the grid was rapidly plunged into liquid ethane and wrapped into a liquid nitrogen environment. Measurements were made in a Talos F200X (Thermo Scientific, Waltham, MA, USA) microscope at $200 \mathrm{kV}$. Cryo-EM images were measured in fresh samples (1 day) and after 8 months of storage at $4{ }^{\circ} \mathrm{C}$ to observe possible changes in the samples' structure over time.

\subsection{In Vitro Tests \\ 2.6.1. Cell Viability Assay}

The experiments were carried using murine fibroblasts (NIH/3T3) and murine melanoma cells (B16-F10) as well as in human keratinocytes (HaCaT) and human melanoma (SK-MEL103) cells. The cells were cultured in DMEM medium supplemented with $10 \%$ fetal bovine

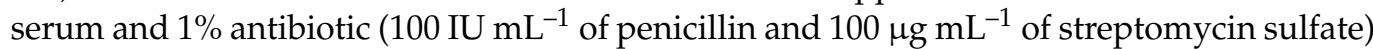
up to the logarithmic phase of growth, in $75 \mathrm{~cm}^{2}$ culture flasks at $37^{\circ} \mathrm{C}$ in a humid atm with $5 \% \mathrm{CO}_{2}$. Cytotoxicity was assessed using the MTT test [33] in 96-well plates at a concentration of $1 \times 10^{4}$ (B16-F10 and SK-MEL-103) and $2 \times 10^{4}(\mathrm{NIH} / 3 \mathrm{~T} 3$ and HaCaT) cells per well. First, the cytotoxicity of the control (drug-free) samples NLC $_{\text {CTRL }}$ and HGel $_{C T R L}$ was investigated. For this, the cells were treated with increasing concentrations $\left(10^{3-} 10^{13}\right.$ particles $/ \mathrm{mL}$ for $\mathrm{NLC}_{\mathrm{CTRL}}$ and $0.01-6.25 \% w / w$ hydrogel for $\mathrm{HGel}_{\mathrm{CTRL}}$ ) corresponding to those used in the formulations. The formulations $\left(\mathrm{DTX}_{\mathrm{T}-\mathrm{HYD}}, \mathrm{NLC}_{\mathrm{DTX}}, \mathrm{NLC}_{\mathrm{DTX}}+\mathrm{LDC}\right.$,

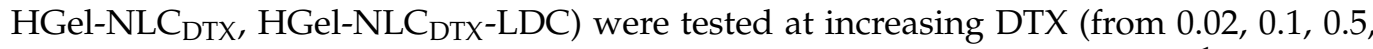
2 and $8 \mu \mathrm{mol} / \mathrm{mL}$ ) and LDC concentrations $\left(0.03,0.1,0.6,2.5\right.$ and $\left.10 \mathrm{mmol} \mathrm{L}^{-1}\right)$, for 24 or 
$72 \mathrm{~h}$. Cell viability was determined by the MTT method and the half-maximal inhibitory concentration $\left(\mathrm{IC}_{50}\right)$ was calculated. Statistical analyses were conducted by Two-way ANOVA with post-hoc Bonferroni $\left({ }^{*} p<0.05 ;{ }^{* *} p<0.01 ;{ }^{* * *} p<0.001\right)$, with the GraphPad Prism version 6.04 for Windows (GraphPad Software, La Jolla, CA, USA).

\subsubsection{Analysis of Colony Formation (Clonogenic Assay)}

The experiments were carried out with the two melanoma cell lines: B16-F10 and SK-MEL-103, from mice and human, respectively. The cells $\left(5 \times 10^{5} /\right.$ well $)$ were seeded in 6 well plates; after $24 \mathrm{~h}$ they were treated with $\mathrm{IC}_{50}$ concentrations of either DTX $\mathrm{T}_{\mathrm{HYD}}, \mathrm{LDC}$,

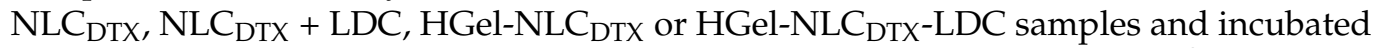
under cell growth conditions. After $24 \mathrm{~h}$, the cells were seeded again at $1 \times 10^{3}$ cells $/$ plate in 6-well plates. Every three days, the culture medium was replaced with DMEM until the 14th day of incubation. After that, the cells were fixed with 1:1 (v:v) methanol:acetone solution, washed with PBS and stained with $0.5 \%(w / v)$ crystal violet for 30 min and analyzed using stereomicroscope.

\subsection{In Vivo Tests}

Female adult (12 weeks old) C57BL/6J mice were obtained from the Multidisciplinary Center for Biological Research (CEMIB-UNICAMP). A total of 50 animals were used in the experiments. The experimental protocol was approved by the UNICAMP Institutional Animal Care and Use Committee (Nb. 5345-1/2019—approved—30 August 2019).

\subsubsection{Anesthetic Efficacy: Tail-Flick Test}

For the anesthetic efficacy test, three groups (5/cage) of animals were used to evaluate the effect of HGel-LDC, HGel-NLC and HGEL-NLC ${ }_{D T X}$-LDC formulations. The mice were maintained with free access to food and water. For the test they were placed in a restraint over an analgesimeter, with a portion of the tail $(5 \mathrm{~cm}$ from the top) exposed to the heat of a projector lamp $\left(55 \pm 1^{\circ} \mathrm{C}\right)$. A thirty-seconds cut-off time was adopted to avoid any thermal injury [34], and the baseline (normal response to the noxious stimulus) was registered. For the blockage of the caudal nerve, hydrogel samples $(0.025 \mathrm{~g})$ containing $2 \%$ LDC were applied on the back of the mice tail and occluded. The analysis started $30 \mathrm{~min}$ after hydrogel administration and the data were recorded every 30 min during the first $1 \mathrm{~h}$, and every $60 \mathrm{~min}$ up to the end of the experiment $(3 \mathrm{~h})$. Data were expressed as percentage of maximum effect (\% MPE), and the area under the curves was calculated. The statistical analyses were performed by Two-way ANOVA plus Tukey post hoc, $n=6$ using the GraphPad Prism version 6.04 for Windows (GraphPad Software, La Jolla, CA, USA).

\subsubsection{Anticancer Tests in Melanoma Mice}

B16-F10 cells ( $10^{6}$ cells per mouse) were subcutaneously injected into the right flank of the mice for tumor induction [35]. Tumors were allowed to grow for 8 days (to approximately $100 \mathrm{~mm}^{3}$ ) prior to the treatments with the hydrogel formulations.

The animals were then randomly divided into seven groups (five mice/group): group 1 = control without tumor (Naive); group 2 = tumor + saline (Positive control, intratumorally

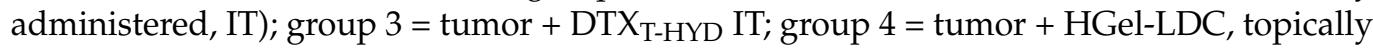
administered (TP); group $5=$ tumor + HGel-NLC $_{\mathrm{DTX}}$ TP; group $6=$ tumor + HGel-NLC $\mathrm{DTX}^{-}$ LDC TP; group 7: tumor + NLC $\mathrm{DTX}$ IT + HGel-LDC TP. While animals in the positive control group received only saline $(0.025 \mathrm{~mL}, \mathrm{IT})$ in the tumor region, the other groups were treated either with $0.025 \mathrm{~g}$ of hydrogel samples or $0.025 \mathrm{~mL}$ of $\mathrm{NLC}_{\mathrm{DTX}}$ or DTX $\mathrm{T}_{-\mathrm{HYD}}$, as specified above. The antineoplastic dosage $(10 \mathrm{mg} / \mathrm{kg}$ of DTX) was based on previous studies in the literature [11,36,37]. The chosen LDC concentration (2\%) in HGel-LDC and

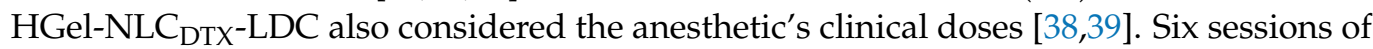
each treatment were carried out, with a one-day interval between sessions. The animals were observed daily and possible signs of clinical impairment (lethargy, inability to walk, and loss of body weight) were assessed. The animals' body mass and food intake were 
quantified weekly, using a PR224 digital analytical scale (OHAUS ${ }^{\circledR}$, Barueri, SP, Brazil). The tumor sizes at specific time points (pre- and post-treatment) were measured with a PD 200 (Vonder $^{\circledR}$, Jundiaí, SP, Brazil) digital caliper and tumor volume $\left(\mathrm{TM}, \mathrm{mm}^{3}\right.$ ) was calculated according to [40]:

$$
\text { Tumor volume }=\frac{\text { tumor length }(\mathrm{mm}) \cdot \text { tumor width }(\mathrm{mm})^{2}}{2}
$$

Tumor volume after 7 days of treatment was also determined from micro-PET/CT, as described further (Section 2.7.4.). The survival probability of the groups was calculated by the Kaplan-Meier method [41]. The non-parametric log-rank test was used to compare the curves between the groups. The GraphPad Prism version 6.04 (GraphPad Software, La Jolla, CA, USA) generated the statistical data, $p<0.05$ was considered significant.

\subsubsection{Tumor Regression Analysis by In Vivo Imaging (Micro-PET/CT)}

Micro-PET/CT analyzes were performed according to the protocol suggested by [42]. Post-treatment tumor regression was analyzed anatomically by computed microtomography (micro-CT), and metabolically by positron emission microtomography (micro-PET) [43]. The images were acquired in a micro-PET/SPECT/CT equipment (Bruker Biospin Corporation, Woodbridge, CT, USA) at the Preclinical Images Lab., School of Medical Sciences, UNICAMP. Tumor characterization was followed 7 days after the last treatment session. For the analyses, the animals were anesthetized with isoflurane (1-2\%), placed in the animal carrier of the equipment, and fixed in the prone position to prevent movements during the scanning. Whole-body micro-CT of the animals was performed. To perform the micro-PET analyses, animals were injected with $\sim 250 \mu \mathrm{Ci}$ of the radiopharmaceutical ${ }^{18} \mathrm{~F}$-[FDG]. Micro$\mathrm{CT}$ acquisition/reconstruction parameters were: total time $60 \mathrm{~min}$, FOV $70 \mathrm{~mm}, 2$ beds, $\mathrm{kVp}=35, \mathrm{~mA}=400 \mu \mathrm{A}$, projections $=1000, \mathrm{FBP}$ and dering $=4$. Micro-PET acquisition parameters were: total time $20 \mathrm{~min}$, FOV $148 \mathrm{~mm}, 1$ bed, MLEM $=6$ interaction. Volumes of interest (VOIs) were drawn by the threshold technique and after logical/morphological operations the parameters $\% \mathrm{ID}_{\mathrm{MAX}}$ and $\% \mathrm{ID}_{\text {Mean }}$ were obtained, for tumor $(\mathrm{T})$, adjacent normal tissue (BG) and liver (L). From them, the ratios $\left(\% \mathrm{ID}^{[\mathrm{T} / \mathrm{BG}]}{ }_{\mathrm{Max}}, \% \mathrm{ID}^{[\mathrm{T} / \mathrm{BG}]}\right.$ Mean $\% \mathrm{ID}^{[\mathrm{T} / \mathrm{L}]} \mathrm{Max}$ and $\% \mathrm{ID}^{[\mathrm{T} / \mathrm{L}]}$ Mean $)$ were calculated. Other semiquantitative metabolic parameters such as metabolic tumor volume (MTV) and total lesion glycolysis (TLG) were calculated [43].

\subsubsection{Serum Biochemical Analytes Measurement}

Ten days after the last treatment session, the animals were euthanized by the intraperitoneal administration of ketamine $(300 \mathrm{mg} / \mathrm{kg})$ and xylazine $(30 \mathrm{mg} / \mathrm{kg})$ strictly following the guidelines of the National Committee of Animal Experimentation (CONCEA, Brasília, DF, Brazil). Immediately after euthanasia, blood samples were collected by cardiac puncture for biochemical analyzes (serum). Immediately after euthanasia, blood samples were collected from the animals by cardiac puncture (with 23 gauge needle and $1 \mathrm{~mL}$ syringe) and the biochemical analytes creatinine, urea (mg/dL), AST and ALT (IU/L) were measured in serum. The analyses were performed using appropriate kinetic methods, in an Hemovet 2300 automated device (São Paulo, SP, Brazil).

\subsubsection{Histological Analysis}

After euthanasia and blood collection, the mice were placed on an operating field for removal of the lungs, liver, spleen, kidneys, and tumor/skin. All organs were weighed using an analytical digital scale. Histopathology of tumor, liver, lung, spleen, and kidney sections was evaluated using the hematoxylin and eosin (H\&E) method. Tissues were fixed with paraformaldehyde, dehydrated, sectioned, and processed for H\&E staining. Histopathological analyses were performed in an inverted Eclipse TS100 microscope (Nikon Instruments Inc., USA) with a color CMOS digital capture camera (Micron Scientific, Brazil) at $100 \times$ and $400 \times$ magnifications. 


\section{Results and Discussion}

\section{1. $N L C_{D T X}$ Preparation and Characterization}

The first challenge to prepare a DTX formulation is imposed by its low aqueous solubility. Thus, considering our previous experience in the encapsulation of hydrophobic drugs [44-46] we decided to encapsulate DTX into NLC. For that, a $1 \%(w / w)$ NLC $_{\mathrm{DTX}}$ formulation and its control (without drug, $\mathrm{NLC}_{\mathrm{CTRL}}$ ) were prepared. As shown in Table 1 , the incorporation of DTX did not significantly change the average size, polydispersity and zeta potential of the NLC. The physical stability of the nanoparticles, as predicted by the homogeneity of their size distribution $(\mathrm{PDI}<0.15)$ and ZP values different from zero, was kept for 12 months of storage at $25^{\circ} \mathrm{C}$ (Figure S1, Supplementary Material). As expected [11], the high encapsulation efficiency $(>97 \%)$ and drug load capacity $(7.5 \%)$ in Table 1 confirm the preference of DTX for the lipid environment of the nanoparticles.

Table 1. Characterization of NLC formulations with ( $\left.\mathrm{NLC}_{\mathrm{DTX}}\right)$ and without DTX (NLC $\left.\mathrm{CTRL}\right)$ in terms of size, polydispersity index (PDI), zeta potential (ZP), encapsulation efficiency (\%EE) and drug loading (\%).

\begin{tabular}{cccccc}
\hline Formulation & $\begin{array}{c}\text { Size } \\
(\mathbf{n m})\end{array}$ & PDI & $\begin{array}{c}\text { ZP } \\
(\mathbf{m V})\end{array}$ & \%EE & Drug Loading (\%) \\
\hline $\mathrm{NLC}_{\mathrm{CTRL}}$ & $222.6 \pm 8.5$ & $0.15 \pm 0.04$ & $-25.9 \pm 0.2$ & - & - \\
$\mathrm{NLC}_{\mathrm{DTX}}$ & $214.0 \pm 10.9$ & $0.09 \pm 0.01$ & $-24.2 \pm 0.3$ & $97.3 \pm 2.6$ & $7.47 \pm 0.26$ \\
\hline
\end{tabular}

\subsection{Hybrid Hydrogel Development and Characterization}

In the next step NLC were incorporated into hydrogels. For the development of XANCHT hydrogels ( $\mathrm{HGel}_{\mathrm{CTRL}}$ ), five blends with different proportions of each biopolymer (samples 1-5 in Table S1) were tested, to find the best consistency and homogeneity. The choice also considered the highest possible concentration of chitosan, to take advantage of its intrinsic antifungal, bactericidal and healing properties [47,48]. All blends but sample 1 showed suitable compatibility between the matrices. Sample 1 (Figure S2A), containing $2.5 \%$ xanthan $+1.5 \%$ chitosan, showed a heterogeneous aspect and was discarded. Sample 2, with $3.3 \%$ xanthan $+1 \%$ chitosan, was selected. LDC was then dispersed into this hydrogel, that remained translucent even after adsorption of the anesthetic (Figure S2B). Further incorporation of NLC turn the hydrogels whitish (as shown in Figure S2C,D).

Oscillatory rheology measurements were then conducted with the different hydrogel

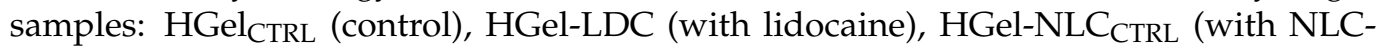

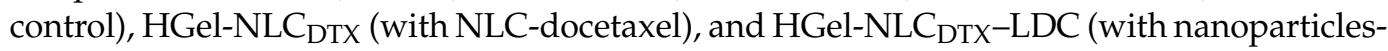
docetaxel and lidocaine). The results in Figure 1A and Table S2 show the rheological parameters $\left(G^{\prime}, G^{\prime \prime}, G^{\prime} / G^{\prime \prime}\right.$ and $\eta$ ) measured at $32.5^{\circ} \mathrm{C}$, the surface temperature of the skin. The frequency sweep analysis revealed the influence of nanoparticles and drug incorporation into the hydrogels structural network. Incorporation of both drugs reduced the apparent viscosity values and the $G^{\prime} / G^{\prime \prime}$ ratios when compared to control gels but maintained the prevalence of $G^{\prime}$ over $G^{\prime \prime}$ modulus. These results strongly suggest that all samples could be topically applied and recover their structure even under shear stress conditions such as those caused by spread on skin surface, improving the drug residence time on the application site [49]. 

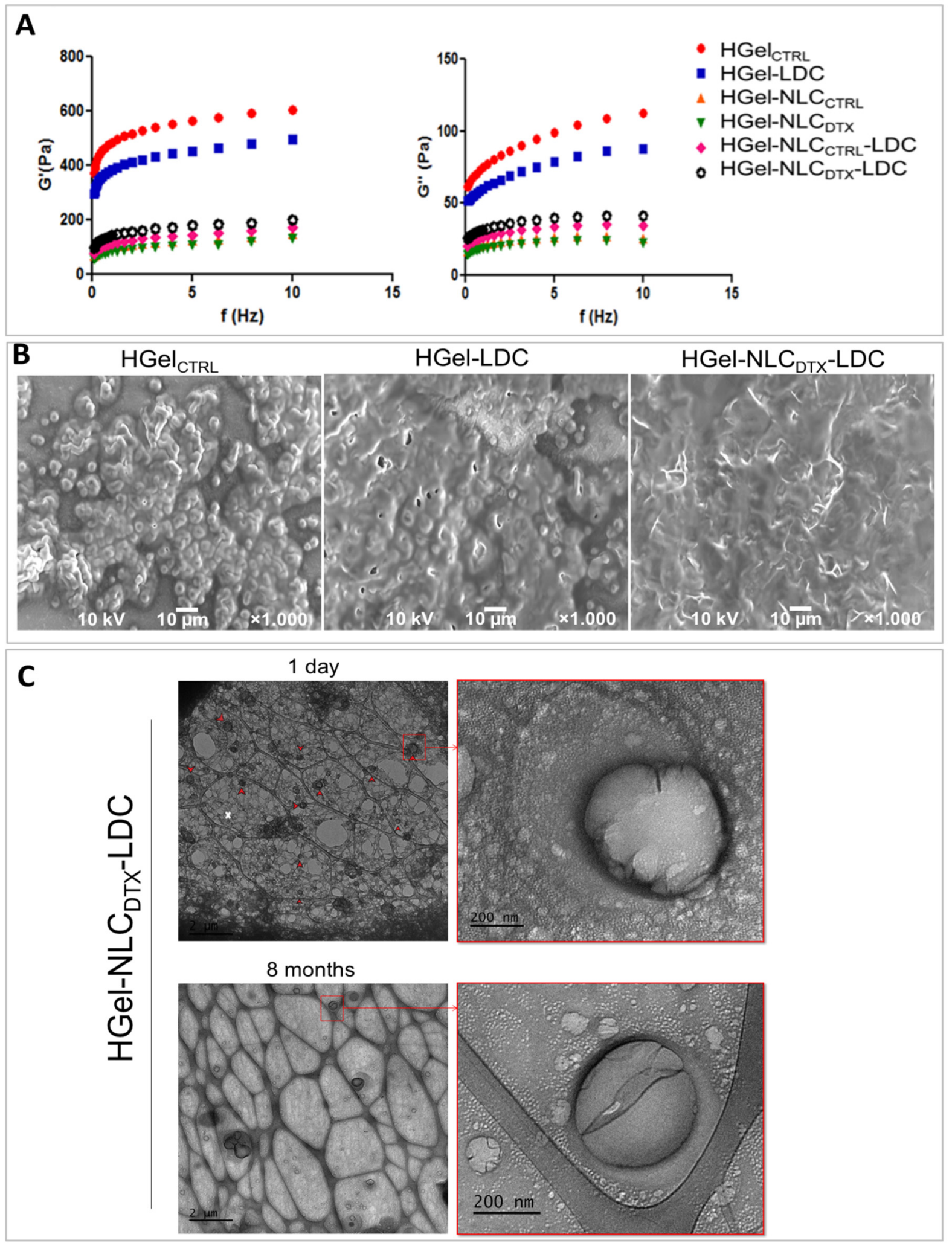

Figure 1. (A) Determination of the viscoelastic properties of hydrogels using oscillatory rheometry, at $32.5^{\circ} \mathrm{C}$ : Elasticity

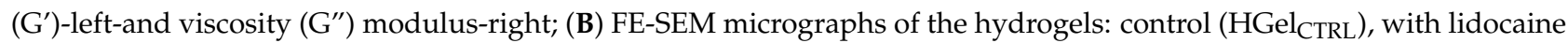
(HGel-LDC) and with lidocaine plus NLC DTX $_{\text {(HGel-NLC }}$ DTX-LDC). Magnification: $1000 \times, 10 \mathrm{kV}$. (C) Cryo-EM of the hybrid hydrogel (HGel-NLC DTX $_{-L D C)}$, at $120 \mathrm{kV}$. Red arrows point to NLC $_{\text {DTX }}$ dispersed in the freshly prepared hydrogel (upper left). Notice that the spherical morphology of the NLC was preserved when adsorbed in the hydrogel lattice, even after 8 months (bottom). Magnification: 60,000× (left) and 120,000 $\times$ (right). 
On the other hand, the presence of the nanoparticles in the hybrid hydrogels (HGelNLC $_{\text {CTRL }}$ and HGel-NLC $C_{\text {DTX }}$ ) was accompanied by reduced $G^{\prime} / G^{\prime \prime}$ and apparent viscosity $(\eta)$ values (Table S2), suggesting NLC interference in the biopolymer network arrangement and hydrogel structural organization.

It is worth mentioning that the pseudoplastic behavior was kept in all hybrid hydrogels tested at the skin temperature [13]. Such results indicate that the prepared hydrogels can be efficiently spread and preserve their structure without phase separation, being suitable for the application of drugs on the skin $[49,50]$. The polyelectrolyte complexes of XAN (anionic) and CHT (cationic) molecules are responsible for the tridimensional network stability and intrinsic therapeutic properties of this polymeric blend [51].

Morphological hydrogel characterization often uses scanning electron microscopy [52]. Here, FE-SEM micrographs were used to compare the morphological properties of HGel $\mathrm{CTRL}_{\mathrm{C}}$ and HGel-LDC and HGel-NLC $\mathrm{DTX}_{\mathrm{DT}}-\mathrm{LDC}$ hydrogels. As shown in Figure 1B, control $\left(\mathrm{HGel}_{\mathrm{CTRL}}\right)$ and lidocaine-containing hydrogels (HGel-LDC) had amorphous appearance with wrinkled surfaces. Addition of NLC DTX did not change the amorphous structure of the hydrogel, but apparently turned its surface more homogeneous, with a different texture

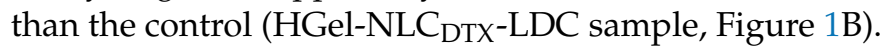

To verify the morphology of NLC into the hybrid hydrogel, cryo-EM analysis was used. As expected, NLC $\mathrm{CTRL}_{\text {TR }}$ and $\mathrm{NLC}_{\mathrm{DTX}}$ samples (suspensions) showed spherical and ellipsoidal structures [53,54], as shown in Figure S3. Most importantly, Figure 1C shows that in the hybrid sample, nanoparticles are distributed in the biopolymer matrix of the XAN-CHT hydrogel in which their spherical morphology and particle size were preserved, even after 8 months of storage (Figure 1C, middle/right).

\subsection{In Vitro Tests}

\subsubsection{Cell Viability Assay}

Four different cell lineages had their viability evaluated: melanoma cancer cells (B16F10 and SK-MEL-103) and non-cancerous cells (NIH/3T3 and HaCaT). The results were compared with those induced by the commercial DTX formulation (docetaxel trihydrateDTX $_{\text {T-HYD }}$ ) and the survival of cells treated with control formulations (NLC $\mathrm{CTRL}_{\text {TR }}$ and $\mathrm{HGel}_{\mathrm{CTRL}}$ ) was also investigated, to exclude any non-specific effects. Cells were treated at equivalent DTX $\left(0.02,0.1,0.5,2\right.$ and $\left.8 \mu \mathrm{mol} \mathrm{mL}^{-1}\right)$ and LDC $(0.03,0.1,0.6,2.5$ and $10 \mathrm{mmol} \mathrm{L}^{-1}$ ) concentrations for $24 \mathrm{~h}$ (Figure 2) and $72 \mathrm{~h}$ (Figure S4). As expected, the control formulations ( $\mathrm{NLC}_{\mathrm{CTRL}}$ and $\mathrm{HGel}_{\mathrm{CTRL}}$ ) were not toxic to any cell line, showing they are safe and suitable for use in intracellular applications.

As for the proposed formulations, the results revealed a reduction in cell viability on non-tumor cells (NIH/3T3 and HaCaT, Figure 2A,B) and tumor cells (B16-F10 and SKMEL-103, Figure 2C,D), treated with free (DTX $\mathrm{T}_{\mathrm{T}-\mathrm{HYD}}$ ) or encapsulated docetaxel (NLC $\mathrm{NTX}_{\mathrm{DT}}$

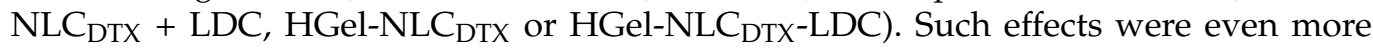
evident after $72 \mathrm{~h}$, as shown in Figure S4. Table 2 shows the calculated half inhibitory concentration $\left(\mathrm{IC}_{50}\right)$ determined after $24 \mathrm{~h}$ of treatment, for docetaxel and lidocaine. The $\mathrm{IC}_{50}$ value for unencapsulated drug DTX (DTX $\mathrm{T}_{\mathrm{TY}}$ ) lied in the expected range of values $(0.01-0.40 \mu \mathrm{mol} / \mathrm{L})$ reported by previous studies in other tumor and non-tumoral cell lines $[55,56]$.

Encapsulation into NLC $_{\text {DTX }}$ and HGel-NLC $C_{\text {DTX }}$ determined significant $(p<0.05)$ reduction in the toxicity of DTX against all evaluated cell lines, within $24 \mathrm{~h}$ of treatment, as shown by the increased $\mathrm{IC}_{50}$ values (Table 2). Similar changes in cytotoxic response were observed by other authors that used lipid nanocarriers for DTX delivery [11,57] or a thermoreversible gel containing adsorbed $\mathrm{NLC}_{\mathrm{DTX}}$ for the treatment of breast cancer [58]. In all cases, the authors attributed the decrease in cytotoxicity (regarding DTX $\mathrm{T}_{\mathrm{T}-\mathrm{HYD}}$ ) to the sustained release of docetaxel from such hybrid systems, which also explains the increase in cytotoxicity registered after $72 \mathrm{~h}$ of treatment (Figure S4). 

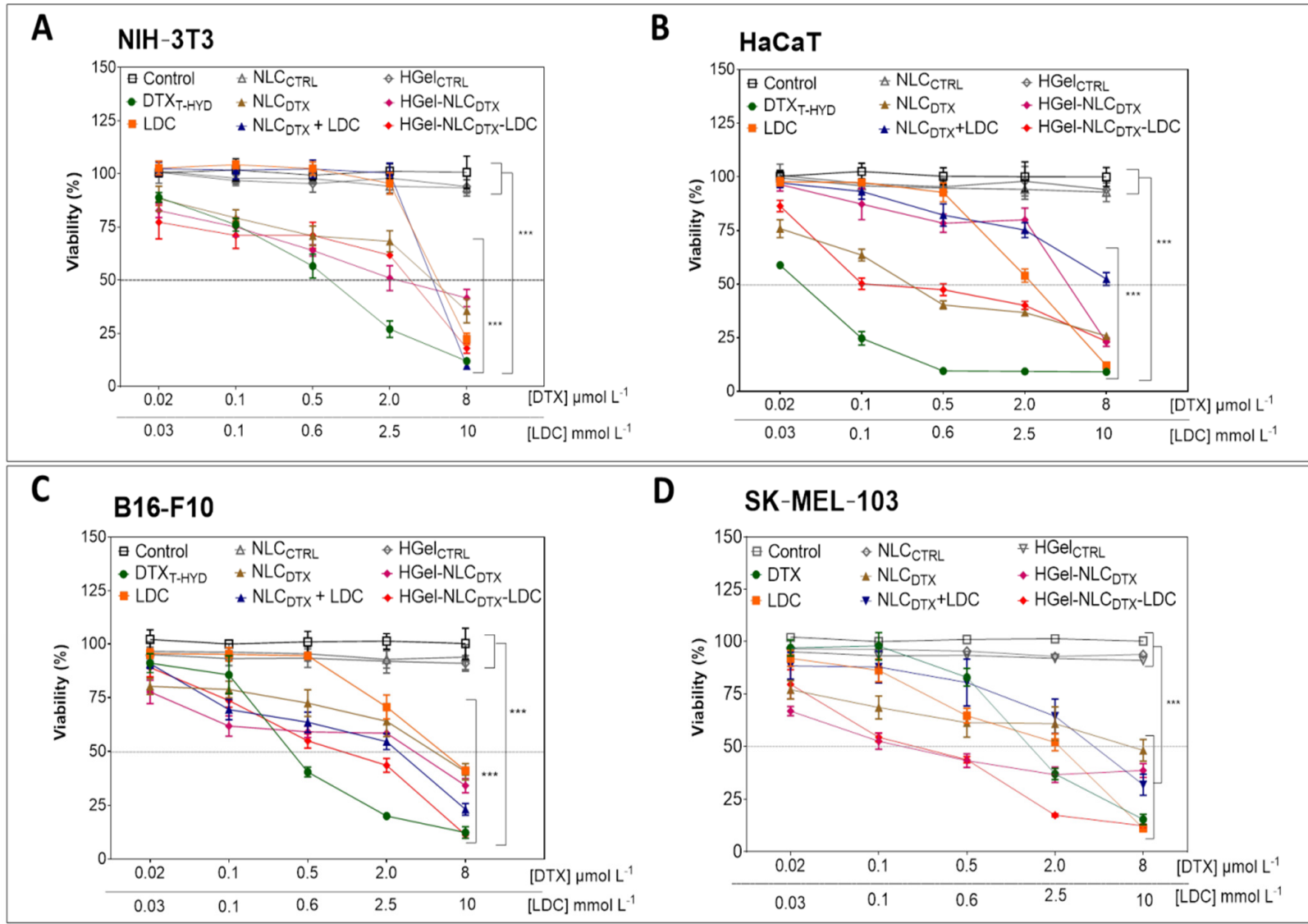

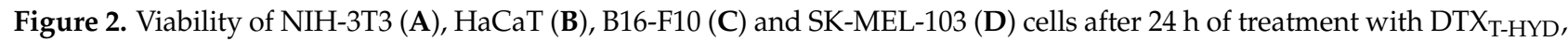

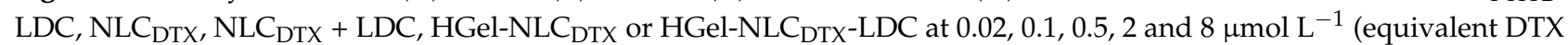
concentrations) and $0.03,0.1,0.6,2.5$ and $10 \mathrm{mmol} \mathrm{L}^{-1}$ (equivalent LD concentrations, evaluated by MTT assay. In the statistical analyses (by two-Way ANOVA plus Bonferroni post-hoc) each treatment was compared to untreated (control) cells. In NIH-3T3 and B16-F10 cells, the DTX formulations showed a significant reduction ${ }^{* * *} p<0.001$ ) in cell viability at the concentrations of $0.02 \mu$ mol L ${ }^{-1}$ docetaxel and above. The same pattern of cytotoxicity was observed in SK-MEL-103 cells, except for the DTX formulation for which a significant reduction in cell viability (*** $p<0.001$ ) was only observed from the concentration of $0.5 \mu \mathrm{mol} \mathrm{L}{ }^{-1}$ docetaxel on. For HaCaT cells the DTX, NLC DTX $_{\text {and HGel-NLC }}$ DTX-LDC formulations promoted significant reduction $(* * *<0.001)$ in cell viability beginning at $0.02 \mu \mathrm{mol} \mathrm{L}{ }^{-1}$ docetaxel, while the $\mathrm{NLC}_{\mathrm{DTX}}+\mathrm{LDC}$ formulations and HGel-NLC $\mathrm{DTX}_{\text {significantly }}$ reduced $\left.{ }^{* * *} p<0.001\right)$ cell viability from the concentration of $0.1 \mu \mathrm{mol} \mathrm{L}{ }^{-1}$ docetaxel and higher. Data expressed as mean $\pm \mathrm{SD}(n=3)$.

Table 2. IC $_{50}$ values of docetaxel (DTX) and lidocaine (free or encapsulated) against NIH-3T3, HaCaT, B16-F10 and SKMEL-103 cells, after $24 \mathrm{~h}$ of treatments, as measured through the MTT assay. Analysis made with the GraphPad Prisma 6.04 software (mean $\pm \mathrm{SD}, n=3$ ) of the values taken from the curves in Figure 2.

\begin{tabular}{|c|c|c|c|c|c|c|c|c|}
\hline \multirow[b]{3}{*}{ Formulations } & \multicolumn{4}{|c|}{ Non-Cancerous Cell Lines } & \multicolumn{4}{|c|}{ Cancer Cell Lines } \\
\hline & \multicolumn{2}{|c|}{$\begin{array}{l}\text { NIH-3T3 } \\
\text { (Murine) }\end{array}$} & \multicolumn{2}{|c|}{$\begin{array}{c}\text { HaCaT } \\
\text { (Human) }\end{array}$} & \multicolumn{2}{|c|}{$\begin{array}{c}\text { B16-F10 } \\
\text { (Murine) }\end{array}$} & \multicolumn{2}{|c|}{ SK-MEL-103 (Human) } \\
\hline & $\begin{array}{c}\text { IC }_{50} \text { of } \\
\text { DTX } \\
\left.(\mu \mathrm{mol} \mathrm{L})^{-1}\right)\end{array}$ & $\begin{array}{c}\mathrm{IC}_{50} \text { of } \\
\text { LDC } \\
\left(\mathrm{mmol} \mathrm{L}^{-1}\right)\end{array}$ & $\begin{array}{c}\mathrm{IC}_{50} \text { of } \\
\text { DTX } \\
\left(\mu \mathrm{mol} \mathrm{L}^{-1}\right)\end{array}$ & $\begin{array}{c}\mathrm{IC}_{50} \text { of } \\
\text { LDC } \\
\left(\mathrm{mmol} \mathrm{L}^{-1}\right)\end{array}$ & $\begin{array}{c}\text { IC }_{50} \text { of } \\
\text { DTX } \\
\left(\mu \mathrm{mol} \mathrm{L}^{-1}\right)\end{array}$ & $\begin{array}{c}\mathrm{IC}_{50} \text { of } \\
\text { LDC } \\
\left(\mathrm{mmol} \mathrm{L}^{-1}\right)\end{array}$ & $\begin{array}{c}\mathrm{IC}_{50} \text { of } \\
\text { DTX } \\
\left(\mu \mathrm{mol} \mathrm{L} \mathrm{L}^{-1}\right)\end{array}$ & $\begin{array}{c}\mathrm{IC}_{50} \text { of } \\
\text { LDC } \\
\left(\mathrm{mmol} \mathrm{L}^{-1}\right)\end{array}$ \\
\hline $\mathrm{DTX}_{\mathrm{T}-\mathrm{HYD}}$ & $0.32 \pm 0.53$ & - & $0.03 \pm 0.03$ & - & $0.40 \pm 0.48$ & - & $0.33 \pm 0.45$ & - \\
\hline LDC & - & $4.95 \pm 5.60$ & - & $2.67 \pm 2.92$ & - & $6.13 \pm 5.44$ & - & $3.26 \pm 1.84$ \\
\hline NLC $_{\text {DTX }}$ & $2.71 \pm 4.53$ & - & $2.29 \pm 2.84$ & - & $3.53 \pm 4.27$ & - & $5.27 \pm 3.47$ & - \\
\hline $\mathrm{NLC}_{\mathrm{DTX}}+\mathrm{LDC}$ & $2.63 \pm 2.95$ & $3.29 \pm 3.69$ & $1.83 \pm 3.92$ & $2.83 \pm 3.53$ & $2.08 \pm 1.76$ & $1.30 \pm 2.21$ & $1.32 \pm 2.25$ & $2.18 \pm 3.21$ \\
\hline HGel-NLC ${ }_{\text {DTX }}$ & $1.24 \pm 2.70$ & - & $3.72 \pm 3.09$ & - & $2.15 \pm 1.54$ & - & $1.55 \pm 1.00$ & - \\
\hline HGel-NLC ${ }_{\mathrm{DTX}}-\mathrm{LDC}$ & $0.71 \pm 1.43$ & $0.86 \pm 1.73$ & $0.29 \pm 0.53$ & $0.34 \pm 0.68$ & $0.81 \pm 1.34$ & $0.97 \pm 1.65$ & $0.28 \pm 0.23$ & $0.32 \pm 0.10$ \\
\hline
\end{tabular}


On the other hand, free LDC had different dose-dependent cytotoxic profiles for each cell line (Figure 2). After $24 \mathrm{~h}$ the greater cytotoxic effect was observed with SK-MEL103 cells, with reduction in cell viability from the concentration of $0.03 \mathrm{mmol} \mathrm{L}^{-1}$ on. For the $\mathrm{HaCaT}$ and B16-F10 strains, cytotoxicity was observed at concentrations higher than $0.6 \mathrm{mmol} . \mathrm{L}^{-1}$ and in NIH-3T3 cells a reduction in cell viability at $2.5 \mathrm{mmol} . \mathrm{L}^{-1}$ or higher LDC concentrations. Curiously, the $\mathrm{IC}_{50}$ of LDC (Table 2) was higher in murine (NIH-3T3: $4.95 \pm 5.60 \mathrm{mmol} \mathrm{L}^{-1}$; B16-F10: $6.13 \pm 5.44 \mathrm{mmol} \mathrm{L}^{-1}$ ) than in human (HaCaT: $2.67 \pm 2.92 \mathrm{mmol} \mathrm{L}^{-1}$; SK-MEL-103: $3.26 \pm 1.84 \mathrm{mmol} \mathrm{L}^{-1}$ ) lineages. Table 2 also shows that the addition of LDC to the $\mathrm{NLC}_{\mathrm{DTX}}$ system (NLC $\mathrm{DTX}_{\mathrm{LDC}}+\mathrm{LD}$ ) increased the cytotoxicity of the formulation against all cell lineages, as seen by the lower $\mathrm{IC}_{50}$ compared to $\mathrm{NLC}_{\mathrm{DTX}}$ formulation. A closer look at Figure 2 in the highest tested concentrations $\left(8 \mu \mathrm{mol} \mathrm{L}{ }^{-1}\right.$ DTX and $\left.10 \mathrm{mmol} \mathrm{L}{ }^{-1} \mathrm{LDC}\right)$ demonstrates the potentializing cytotoxic effect of LDC on NIH-3T3, B16-F10 and SK-MEL-103 cells. The viability of NIH-3T3 cells (35\% when treated with NLC $_{\text {DTX }}$ ) decreased to 9\% when LDC was added to the system $\left(\mathrm{NLC}_{\mathrm{DTX}}+\mathrm{LDC}\right)$; the same was observed for the hydrogel formulations: $52 \%$ cell viability

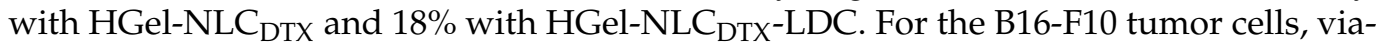
bility was $40 \%$ when using NLC $_{\text {DTX }}$ and $23 \%$ with NLC $_{\text {DTX }}+$ LDC; in the hydrogels the

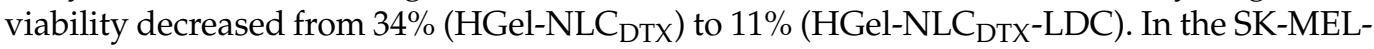
103 tumor lineage cell viability $\left(48 \%\right.$ with NLC $_{\text {DTX }}$ ) decreased to $32 \%$ with NLC $_{\text {DTX }}+$ LDC;

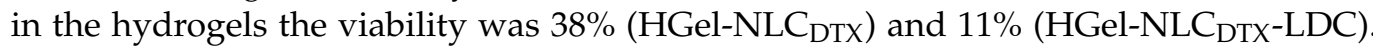
Only the HaCaT strain showed a different profile, with $26 \%$ cell viability after treatment with the NLC $_{\text {DTX }}$ formulation and $52 \%$ when lidocaine was present (NLC DTX LDC) and almost no variation between the hydrogel formulations (23\% for HGel-NLC DTX and $24 \%$

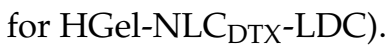

As for the cytotoxic effect of LDC, Karniel \& Beitner demonstrated a significant and dose-dependent reduction in the activity of glucose 1,6-biphosphate and fructose 1,6-biphosphate in melanoma cells (B16) after treatment with the anesthetic, showing that its cytotoxicity was correlated with ATP depletion [59]. In 2008, Desai and coworkers verified that LDC affected the multiplication of NIH-3T3 cells, decreasing DNA synthesis by favoring the expression of cyclin 1A-dependent kinase inhibitor p21 [60]. Furthermore, in some resistant neoplastic cells such as B16-F10, LDC was found to act as a chemosensitizer to other conventional chemotherapeutics [26].

Overall, a time and dose-dependent cytotoxic activity was observed for all formulations and cell lines evaluated. Encapsulation decreased the toxicity of DTX while LDC intrinsic cytotoxicity explains the lower cell survivor rates observed in formulations containing DTX and the anesthetic $\left(\mathrm{NLC}_{\mathrm{DTX}}+\mathrm{LDC}_{\text {vs. }} \mathrm{NLC}_{\mathrm{DTX}}\right.$ and HGel-NLC $\mathrm{DTX}_{\mathrm{DTC}}$ Ls. HGel-NLC $\left.{ }_{\text {DTX }}\right)$, against all cell lineages.

\subsubsection{Evaluation of Cell Reproductive Viability (Clonogenic Assay)}

The clonogenic assay is a consistent method to determine if the cell can proliferate/form colonies after being exposed to anti-tumor agents [61]. The top lane of Figure 3 shows that control (Naive) cells and those treated with NLC CTRL $_{\text {and HGelC }}$ CTRL were able to fully proliferate and form colonies, as a clear sign of no toxicity. On the other hand, the cancer cells treated with $\mathrm{IC}_{50}$ concentrations of free $\left(\mathrm{DTX}_{\mathrm{T}-\mathrm{HYD}}\right.$ or free LDC, Figure 3-middle lane) - or encapsulated drugs (NLC ${ }_{\text {DTX }}, N_{\text {NLC }}$ - ${ }_{\text {DTX }}+$ LDC, HGel-NLC ${ }_{\text {DTX }}$ or HGel-NLC ${ }_{\text {DTX }}$-LDC, Figure 3-bottom lane) visually showed smaller number of colonies than non-treated cells. Such effect was evident for cells treated with either NLC $\mathrm{DTX}_{\text {, }}$

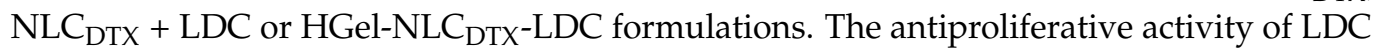
is also noticeable in Figure 3, against both cancer cell types. Such effect was less pronounced than that of free $\mathrm{DTX}_{\mathrm{T}-\mathrm{HYD}}$ or the formulations (see the $\mathrm{IC}_{50}$ values in Table 2). The clonogenic test agrees with the previously shown cell viability data (Table 2, Figure 2 and Figure S4). 


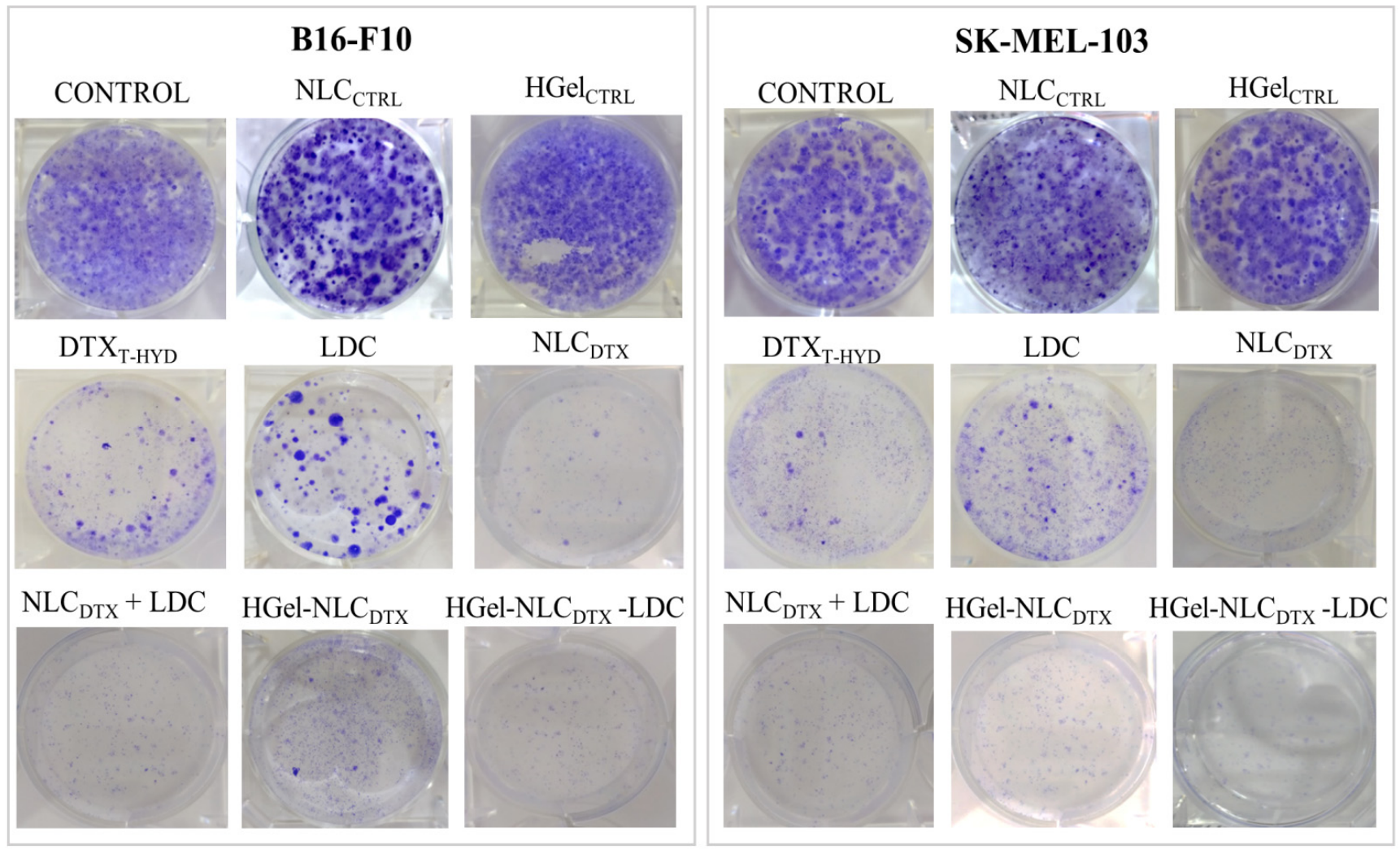

Figure 3. Clonogenic assay. Effect of the treatment with formulations on the ability of cancer (B16-F10) and SK-MEL-103) cells to form colonies.

Interestingly, more cell colonies were observed in cells treated with DTX $\mathrm{T}_{\mathrm{HYO}}$ in comparison to those treated with DTX incorporated into the NLC which should indicate that the cancer cells were less resistant to the cytotoxic effects of nanoformulations containing the antineoplastic than to free docetaxel. This behavior should be related to the internalization and sustained release of DTX promoted by the nanoparticles, since even the fraction of resistant cells (those that would be able to proliferate after treatment with DTX $\mathrm{T}_{\text {-HYD }}$ ) died after $24 \mathrm{~h}$ of treatment with the docetaxel-containing nanoparticles. Similar results were observed with other antineoplastic-based nanoformulations that promoted sustained release $[62,63]$.

\subsection{In Vivo Assays}

3.4.1. Anesthetic Efficacy Determined by the Tail-Flick Test

The tail-flick test is a commonly used method to determine the efficacy of local anesthetics in topical formulations [64]. This assay was performed to evaluate the anesthetic effect of LDC incorporated in the hydrogel formulations (Figure S5). The results of maximum possible effect (MPE) area under the curve (AUC) and anesthesia duration after topical application of hydrogels on the animal tail are shown in Table 3.

Table 3. Tail-flick test in mice. Percent Maximum Possible Effect (MPE), Area under the curve (AUC) and time of anesthesia for the hydrogel lidocaine formulations (HGel-LDC), hydrogel plus NLC $\mathrm{CTRL}$ (HGel-NLC $\mathrm{CTRL}_{\text {) }}$ and hydrogel plus NLC and docetaxel (HGel- NLC $\mathrm{DTX}_{\mathrm{LDC}}$ ).

\begin{tabular}{|c|c|c|c|}
\hline Formulation & $\mathrm{MPE} \pm \mathrm{SD}(\%)$ & $\mathrm{AUC} \pm \mathrm{SD}$ & Time of Anesthesia (min) \\
\hline HGel-LDC & $88.48 \pm 11.39$ & $3545.8 \pm 821.1$ & 150 \\
\hline HGel-NLC ${ }_{C T R L}-L D C$ & $88.85 \pm 15.84$ & $3882.8 \pm 805.2$ & 150 \\
\hline HGel-NLC $_{\text {DTX-LDC }}$ & $88.06 \pm 11.65$ & $4377.8 \pm 950.8$ & 150 \\
\hline
\end{tabular}

Statistical analysis (Tukey's multiple comparisons test, $n=5$ ) showed no significant differences among the groups

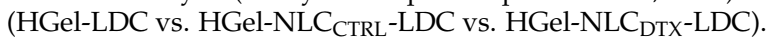


All hydrogel formulations containing LDC showed similar analgesic effect: MPE after $30 \mathrm{~min}$ (Figure S5) and ca. $150 \mathrm{~min}$ of total anesthesia duration. No significant differences ( $p<0.05$, Tukey's multiple comparisons test) were observed among the formulations regarding MPE and AUC confirming that the antinociceptive effect of LDC was preserved in the hydrogels. These results corroborate previous reports in the literature, obtained with commercial LDC (2\%) incorporated or not in gels and tested in mouse through the tail-flick test [65]. Therefore, the XAN-CHT hydrogel did not interfere with the anesthetic activity and could possibly contribute to the pharmaceutical formulation with the intrinsic anti-inflammatory, antifungal and bactericidal properties of the polymers $[47,66,67]$.

\subsubsection{In Vivo Antitumor Efficacy in a Melanoma Model}

The in vivo therapeutic performance of nanohybrid hydrogels was studied in B16-F10 tumor-bearing C57BL/6J mice, treated with six doses of $10 \mathrm{mg} / \mathrm{kg}$ DTX. The dose was selected based on the previous works $[11,36,37]$. The tumor volume grew rapidly in mice treated with saline (positive control) than in those treated intratumorally (IT) or topically (TP) with conventional docetaxel formulation (DTX $\mathrm{T}_{\mathrm{THYD}} \mathrm{IT}$ ) or hydrogels (HGel-LDC TP, HGel-NLC $_{\text {DTX }}$ TP, HGel-NLC DTX $_{\text {-LDC TP and NLC }}$ DTX IT + HGel-LDC TP) as shown in Figure $4 \mathrm{~A}$. In comparison to the positive control all treated groups significantly reduced tumor growth (Two-Way ANOVA post-hoc Bonferroni, ${ }^{* * *} p<0.001$ ) (Figure $4 \mathrm{~B}, \mathrm{C}$ ).

The treatment with free DTX (DTX T-HYD IT) inhibited tumor growth by about $95.0 \%$ at the end point of study. Treatments using the hydrogel with only LDC (HGel-LDC TP) or only NLC $\mathrm{NTX}_{\mathrm{DT}}$ (HGel-NLC $\mathrm{DTX}_{\mathrm{DT}} \mathrm{TP}$ ) inhibited tumor growth by $58.7 \%$ and $62.7 \%$, respectively, while the inhibition with HGel-NLC $\mathrm{DTX}_{\mathrm{DT}} \mathrm{LDC}$ TP reached $75.4 \%$. To compare the efficiency of the formulations with that of free DTX (DTX also tested via intratumor administration associated to the topical application of lidocaine hydrogel (NLC $\mathrm{DTX}_{\mathrm{IT}} \mathrm{IT}$ Hel-LDC TP). In this group, tumor growth inhibition reached $97.0 \%$ at the end of the experiments suggesting a possible synergistic effect between both therapeutic approaches and administration routes.

The significant $(p<0.05)$ inhibition of tumor growth by HGel-LDC TP, HGel-NLC $C_{\text {DTX }}$ TP, HGel-NLC $C_{\text {DTX }}$-LDC TP and NLC DTX $_{\text {IT }}+$ HGel-LDC TP discloses the effectiveness of the treatment using DTX-loaded NLC associated with LDC-based hydrogel. In addition, they reveal the potential of LDC for the treatment of melanoma, in association with an antineoplastic agent. Previous studies pointed out the anticarcinogenic effect of LDC in different tumor models, such as breast [68], bladder [20], squamous and basal cell carcinoma [69], gastric cancer [28] and melanoma cell [19]. A recent review shows that LDC acts as a chemosensitizer to other antineoplastic agents, inhibiting the growth of tumors after single use at different concentrations through the regulation of epigenetic modifications, promotion of pro-apoptotic pathways and angiogenic inhibitor. Its authors advise the repositioning of LDC as an antineoplastic agent [26]. Finally, in addition to the antiproliferative effect on tumor cells, LDC reduces pain and, consequently, may increase the patient compliance to the treatment $[48,70]$.

Here, in the maximum antitumor therapeutic efficacy (equivalent to the conventional formulation with $\mathrm{DTX}_{\mathrm{T}-\mathrm{HYD}} \mathrm{IT}$ ) was observed when $\mathrm{NLC}_{\mathrm{DTX}}$ was intratumorally administered together with the topical application of the LDC-based hydrogel. Such joint of administration routes has been previously proposed by other authors [36,71] and the increased therapeutic effect compared with the topical treatment could be attributed to the higher drug uptake at the tumor site [72-74]. These data open new possibilities for the future investigations of this hybrid system co-delivering LDC and DTX for the treatment of skin cancer. 


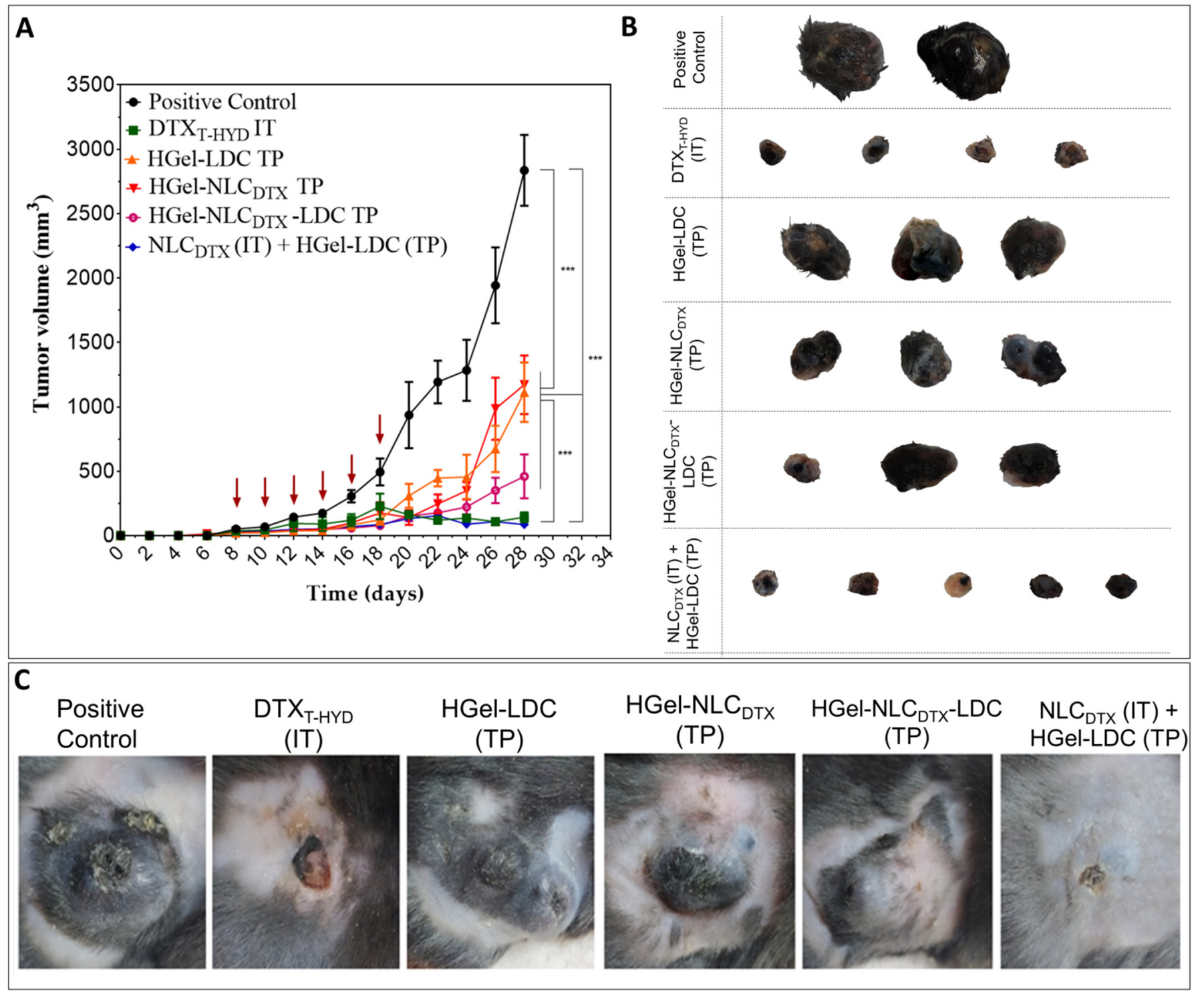

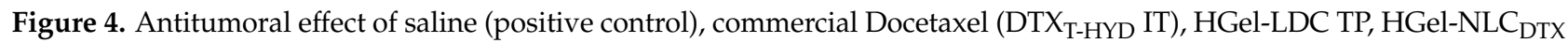
TP, HGel-NLC DTX $_{\text {-LDC TP and NLC }}$ DTX IT + HGel-LDC TP on B16-F10 tumor-bearing C57BL/6J mice. (A) Variation of tumor volume as a function of time after treatment (started at day 8th and subsequently applied on the 10th, 12th, 14th, 16th and 18th day, as indicated by the red arrows). (B) Photographs of tumors from each treatment before euthanasia. (C) Representative images of tumors excised from each treatment group. TP $=$ topical application; IT $=$ intratumor application. Statistical analysis: Two-Way ANOVA post-hoc Bonferroni ( $\left.{ }^{* *} p<0.001\right)$. Data expressed as mean $\pm \operatorname{SD}(n=5)$.

\subsubsection{Tumor Regression Analysis by In Vivo Imaging}

Hybrid imaging of positron emission tomography with 18F-fluorodeoxyglucose and computed tomography $\left({ }^{18} \mathrm{~F}-[\mathrm{FDG}] \mathrm{PET} / \mathrm{CT}\right)$ is a key methodology to evaluate cancer patients [75]. ${ }^{18} \mathrm{~F}$-[FDG] uptake reflects tumor physiology, tumor cell density and the distinction between active lesions or necrotic tissue [43]. In this work we performed the quantification of metabolic tumor volume (MTV), total lesion glycolysis (TLG) and the percentage of maximum ( $\left.\% \mathrm{ID}_{\mathrm{Max}}\right)$ and average $\left(\% \mathrm{ID}_{\text {Mean }}\right)^{18} \mathrm{~F}$-[FDG] injected dose activity in the tumor area. The tissue adjacent to the tumor (BG) and the liver were also evaluated to serve as reference and data normalization (Figure 5). The \%ID of the record is an important reference to estimate the intensity of local metabolic activity, and the liver is one of the organs with the most constant ${ }^{18} \mathrm{~F}$-[FDG] uptake [76]. 


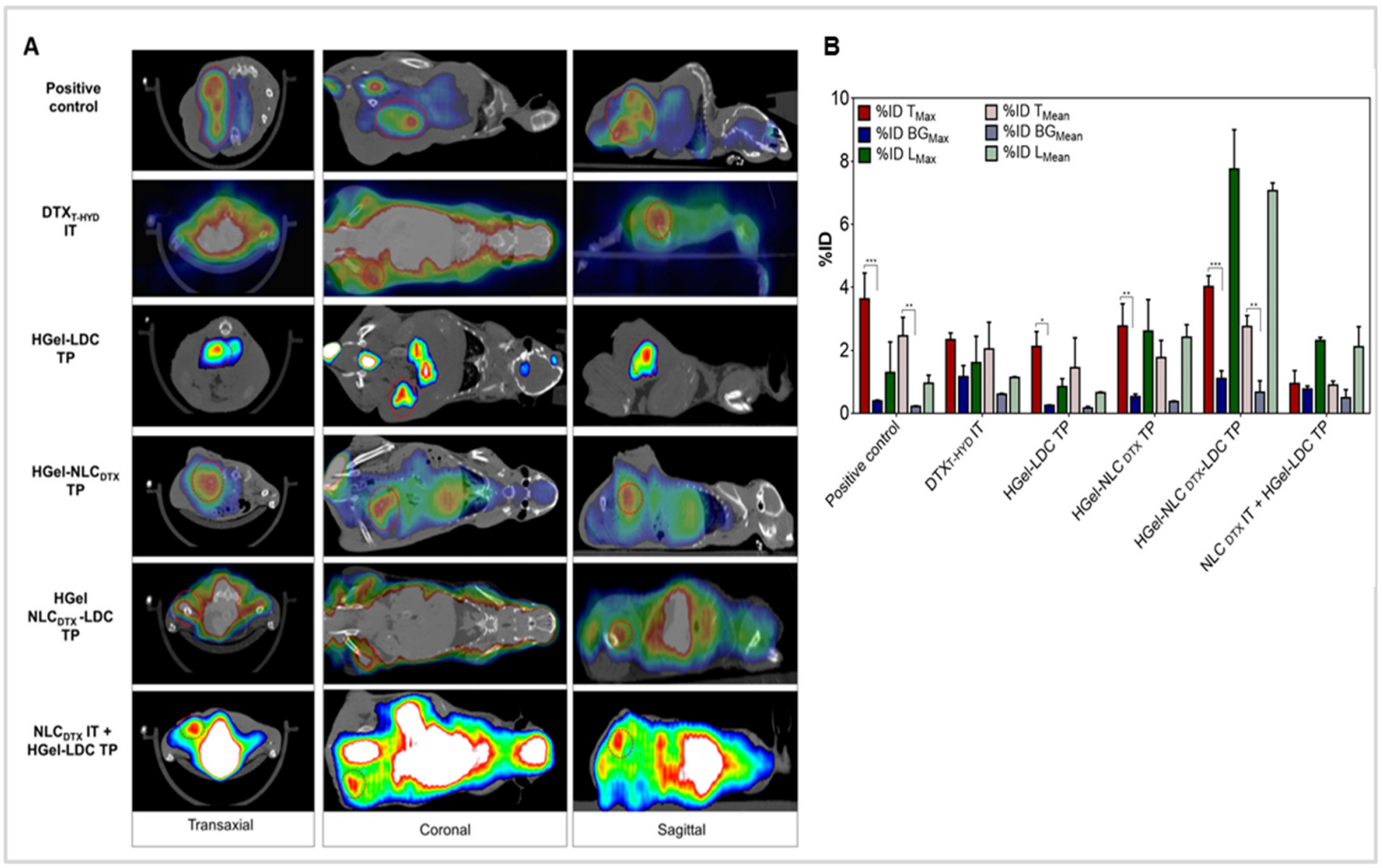

Figure 5. Micro-PET/CT imaging showing ${ }^{18} \mathrm{~F}$-[FDG] uptake in mice with B16-F10 tumors treated with saline (Positive control), free docetaxel (DTX $\mathrm{T}_{\text {-HYD) }}$ and hydrogel formulations (HGel-LDC, HGel-NLC $\mathrm{DTX}$ TP, HGel-NLC $\mathrm{DTX}_{\text {-LDC TP and }}$ NLC $_{\text {DTX }}$ IT + HGel-LDC TP). (A) Images taken 7 days after the end of the treatments. Additional identifiable structures with respect to ${ }^{18} \mathrm{~F}$-[FDG] uptake were bladder, kidney, liver and heart. Dashed circles indicate the location of the tumor. (B) Quantification of ${ }^{18} \mathrm{~F}$-[FDG] uptake (\% $\mathrm{ID}_{\mathrm{Max}}$ and ID\% ${ }_{\text {Mean }}$, mean $\left.\pm \mathrm{SD}, n=2\right)$ in tumors (T), normal adjacent tissue (BG) and liver (L). The $\% \mathrm{ID}_{\text {Max }}$ of the tumor (\% ID $\mathrm{T}_{\mathrm{Max}}$ ) was compared to the $\% \mathrm{ID}_{\mathrm{Max}}-\mathrm{BG}\left(\% \mathrm{ID} \mathrm{BG}_{\mathrm{Max}}\right)$ to better assess the injected dose activity. Raw values are shown in Table S3. The $\% \mathrm{ID}_{\mathrm{Max}}-$ liver (\%ID $\mathrm{L}_{\mathrm{Max}}$ ) and $\% \mathrm{ID}_{\text {Mean }}-$ liver (\%ID $\mathrm{L}_{\mathrm{Mean}}$ served as a reference for high ${ }^{18} \mathrm{~F}-[\mathrm{FDG}]$ uptake. Statistical analysis: Two-Way ANOVA post-hoc Tukey, ${ }^{*} p<0.05 ;{ }^{* *} p<0.01$; *** $p<0.001$.

MTV measures the volume of structures (e.g., tumors) that capture ${ }^{18} \mathrm{~F}-[\mathrm{FDG}]$. TLG can be defined as the sum of the MTV product of each lesion per its standardized uptake value, being an important parameter for the oncological prognosis. Normally, the higher the TLG the worse the individual's prognosis, which can be correlated with a decrease in the overall survival rate and advancement of cancer staging [43,77,78].

According to the TLG values in Table 4, the best prognosis was observed in animals from the group treated with NLC $_{\text {DTX }}$ IT + HGel-LDC TP which showed the lower metabolic activity of tumor cells in the neoplastic region (0.011). It is also noteworthy that the hybrid system (HGel-NLC $\mathrm{DTX}_{\mathrm{DT}}$-LDC TP) group had a prognosis (TLG $\left.=0.095\right)$ similar to that of the conventional treatment with DTX T-HYD IT (0.105). A relatively low $(0.288)$ metabolic activity of tumor cells was determined in the group treated with HGel-LDC TP-confirming

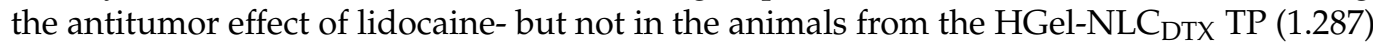
group. As expected, the worst survival prognosis was observed in animals from the positive control group (1.558). 
Table 4. Values estimated by micro-PET/CT analysis of the percent ratio of the maximum or mean injected dose between the tumor region and the adjacent tissue $\left(\% \mathrm{ID}^{[\mathrm{T} / \mathrm{BG}]} \mathrm{Max}\right.$ and \% $\left.\mathrm{ID}^{[\mathrm{T} / \mathrm{BG}]} \mathrm{Mean}\right)$, or liver $\left(\% \mathrm{ID}^{[\mathrm{T} / \mathrm{L}]} \operatorname{Max}\right.$ and \%ID $\left.{ }^{[\mathrm{T} / \mathrm{L}]} \mathrm{Mean}\right)$; tumor metabolic volume (MTV) and total lesion glycolysis (TLG). The anatomical volume of the tumor (TV) measured with an external caliper is also given.

\begin{tabular}{|c|c|c|c|c|c|c|c|}
\hline & & & Micro-PET/C & & & & Caliper \\
\hline Formulations & $\% \mathrm{ID}^{[\mathrm{T} / \mathrm{BG}]} \operatorname{Max}$ & $\% \mathrm{ID}^{[\mathrm{T} / \mathrm{BG}]}$ Mean & $\% \mathrm{ID}^{[\mathrm{T} / \mathrm{L}]} \operatorname{Max}$ & $\% \mathrm{ID}^{[\mathrm{T} / \mathrm{L}]}$ Mean & MTV & TLG & $\mathrm{TV}\left(\mathrm{mm}^{3}\right)$ \\
\hline Positive Control & 9.169 & 11.336 & 2.812 & 2.570 & 0.633 & 1.558 & 3741.68 \\
\hline DTX $_{\text {T-HYD IT }}$ & 2.012 & 3.354 & 1.457 & 1.795 & 0.051 & 0.105 & 41.87 \\
\hline HGel-LDC TP & 8.350 & 8.512 & 2.498 & 2.209 & 0.199 & 0.288 & 752.33 \\
\hline HGel-NLC ${ }_{\text {DTX }}$ TP & 5.205 & 4.752 & 1.060 & 0.731 & 0.728 & 1.287 & 544.01 \\
\hline HGel-NLC ${ }_{\text {DTX-LDC TP }}$ & 3.641 & 4.129 & 0.518 & 0.390 & 0.034 & 0.095 & 155.23 \\
\hline NLC $_{\text {DTX }}$ IT + HGel-LDC TP & 1.230 & 1.806 & 0.410 & 0.423 & 0.012 & 0.011 & 42.60 \\
\hline
\end{tabular}

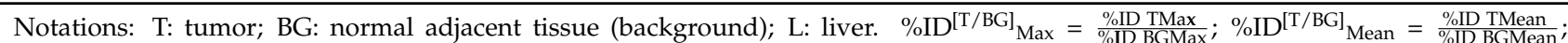
$\% \mathrm{ID}^{[\mathrm{T} / \mathrm{L}]}{ }_{\text {Max }}=\frac{\% \mathrm{ID} \mathrm{TMax}}{\% \mathrm{ID} \mathrm{LMax}} ; \% \mathrm{ID}^{[\mathrm{T} / \mathrm{L}]}{ }_{\text {Mean }}=\frac{\% \mathrm{ID} \text { TMean }}{\% \text { ID LMean }}$. The raw values of $\%$ IDMax and $\%$ IDMean in tumor, adjacent tissue and liver are shown in Table S3.

An additional advantage of micro-PET is the ability to assess the internal metabolic features of a tumor, which cannot be assessed by external calibrator measurements [78]. As shown in Table 4, even the tumor volume being bigger in the positive control, its MTV and TLG values were similar to those of treated groups such as the HGel-NLC DTX TP. Accordingly to Tseng and co-workers [78] tumors larger than $1.000 \mathrm{~mm}^{3}$ develop central photopenia consistent with tumor necrosis. This effect may explain why tumors with large volumes have decreased tumor metabolic activity, and consequent lower in $\% \mathrm{ID}_{\mathrm{MAX}}$ values (Figure 5B). Therefore, the interpretation of data from tumors with volumes $>1.000 \mathrm{~mm}^{3}$ (as in the positive control) should be performed with caution, as tumor necrosis can affect the measurements of tumor volume and mean radiotracer accumulation. Photopenia also explains why larger tumors may have low MTV, as observed here for HGel-LDC TP (Table 4). These findings were confirmed by the presence of necrosis in the histopathological analysis (see Section 3.6).

Normally, undifferentiated tumor cells have more aggressive neoplastic characteristics and are more metabolically active than differentiated ones $[78,79]$. The relation between $\% \mathrm{ID}^{[\mathrm{T} / \mathrm{BG}]}$ Max and \% $\mathrm{ID}^{[\mathrm{T} / \mathrm{BG}]}$ Mean ratios (Table 4), can signal a transition from differentiated to undifferentiated tumor cells, when $\% \mathrm{ID}^{[\mathrm{T} / \mathrm{BG}]} \mathrm{Max}$ is greater than $\% \mathrm{ID}^{[\mathrm{T} / \mathrm{BG}]}$ Mean $[80]$. From a clinical point of view this is very important, since undifferentiated cells generally do not respond well to chemotherapy being at a more advanced stage of the disease. [78]. As discussed above, photopenia, probably caused by tumor necrosis, may have interfered with the quantification of \%ID values in the positive control and HGel-LDC TP groups, curbing the effective analyzes of cell differentiation in those groups. However, for the HGel-NLC $\mathrm{CTX}_{\mathrm{D}}$ LDC TP, DTX T-HYD $_{\text {and NLC }}$ DTX IT + HGel-LDC TP groups, Table 4 shows signs of high cell differentiation (\%ID ${ }^{[\mathrm{T} / \mathrm{BG}]}{ }_{\mathrm{Max}}<\% \mathrm{ID}^{[\mathrm{T} / \mathrm{BG}]}$ Mean $)$ in addition to low $\mathrm{TLG}$ values, as discussed before. An unexpected result was obtained with the HGel-NLC $\mathrm{DTX}_{\mathrm{DT}}$ TP group that showed the highest $\% \mathrm{ID}^{[\mathrm{T} / \mathrm{BG}]} \mathrm{Max} / \% \mathrm{ID}^{[\mathrm{T} / \mathrm{BG}]}{ }_{\text {Mean }}$ ratio (5.205/4.752) suggesting the occurrence of transitions from differentiated cells to undifferentiated cells and neoplasm evolution.

Overall, the micro-PET/CT results confirm macroscopic observation (tumor volume), revealing a prognosis profile of: NLC $_{\text {DTX }}$ IT + HGel-LDC TP $>$ DTX $_{\text {T-HYD }} \geq$ HGel-NLC $_{\text {DTX- }}$

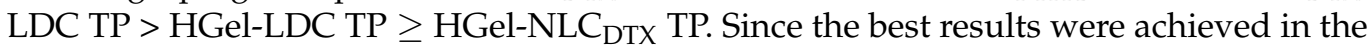
NLC $_{\text {DTX }}$ IT + HGel-LDC TP group, we hypothesize that the low efficacy observed with

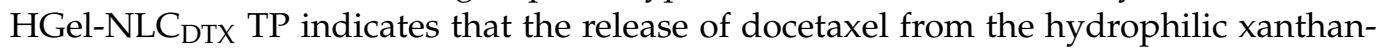
chitosan hydrogel is a limiting step—unlike what was observed for lidocaine (HGel-LDC $\mathrm{TP})$, a more polar compound.

\subsection{Screening of Treatments' Adverse Effects}

3.5.1. Biochemical Analyses

The biochemical analyses of alanine transaminase (ALT), aspartate aminotransferase (AST), creatinine and urea were performed in the blood of treated groups of animals 
(Table 5). Pathological processes in the liver can increase the activity of serum ALT and AST, caused by infections or chemical agents, such as antineoplastic drugs [79] while changes in serum levels of creatinine and urea are indicative of renal overload, nephrotoxicity and acute renal failure [80,81]. Overall, from a clinical point of view the levels of ALT, AST, urea, or creatinine remained normal after all treatments.

Table 5. Biochemical parameters in the serum of female C57BL/6J mice, after treatment with PBS (positive control), free docetaxel (DTX $\mathrm{T}_{\text {-HYD }}$ ) and hydrogel formulations (HGel-LDC, HGel-NLC $\mathrm{DTX}_{\mathrm{TP}}$, HGel-NLC $\mathrm{DTX}_{\text {-LDC TP and NLC }}$ DTX IT + HGel-LDC TP).

\begin{tabular}{|c|c|c|c|c|}
\hline Groups & $\begin{array}{c}\text { ALT } \\
\text { (UI/L) } \\
\text { (Rf:44.0-87.0) }\end{array}$ & $\begin{array}{c}\text { AST } \\
\text { (UI/L) } \\
\text { (Rf:55.0-251.0) }\end{array}$ & $\begin{array}{c}\text { Creatinine } \\
\text { (mg/dL) }\end{array}$ & $\begin{array}{c}\text { Urea } \\
(\mathrm{mg} / \mathrm{dL}) \\
\text { (Rf: } 18.0-31.0)\end{array}$ \\
\hline Naive & $52.0 \pm 6.2$ & $144.0 \pm 10.5$ & $0.66 \pm 0.26$ & $48.0 \pm 18.0$ \\
\hline Positive Control & $171.0 \pm 8.4$ & $20.0 \pm 5.7$ & $0.68 \pm 0.12$ & $57.0 \pm 14.1$ \\
\hline DTX $_{\text {T-HYD }}$ IT & $28.0 \pm 11.0$ & $144.0 \pm 3.4$ & $0.15 \pm 0.09$ & $66.0 \pm 17.9$ \\
\hline HGel-LDC TP & $135.0 \pm 16.0$ & $36.0 \pm 9.0$ & $0.57 \pm 0.10$ & $52.0 \pm 16.3$ \\
\hline HGel-NLC ${ }_{\text {DTX }}$ TP & $34.0 \pm 12.0$ & $186.0 \pm 6.2$ & $0.57 \pm 0.21$ & $43.0 \pm 15.5$ \\
\hline HGel-NLC ${ }_{\text {DTX-LDC TP }}$ & $98.0 \pm 14.4$ & $213.0 \pm 11.4$ & $0.38 \pm 0.14$ & $52.0 \pm 15.0$ \\
\hline NLC $_{\text {DTX IT }}+$ HGel-LDC TP & $45.0 \pm 17.0$ & $51.0 \pm 8.4$ & $0.52 \pm 0.13$ & $45.0 \pm 19.0$ \\
\hline
\end{tabular}

NOTE: ALT, alanine aminotransferase. AST, aspartate aminotransferase. Values represented as mean \pm standard error. Rf $=$ reference range adapted from [82], Comp. Med. 2004.

Additionally, mice weight and feed consumption were not affected by the treatments (as discussed further in Figure 6) showing the negligible systemic toxicity of these different treatments, in the administered doses.
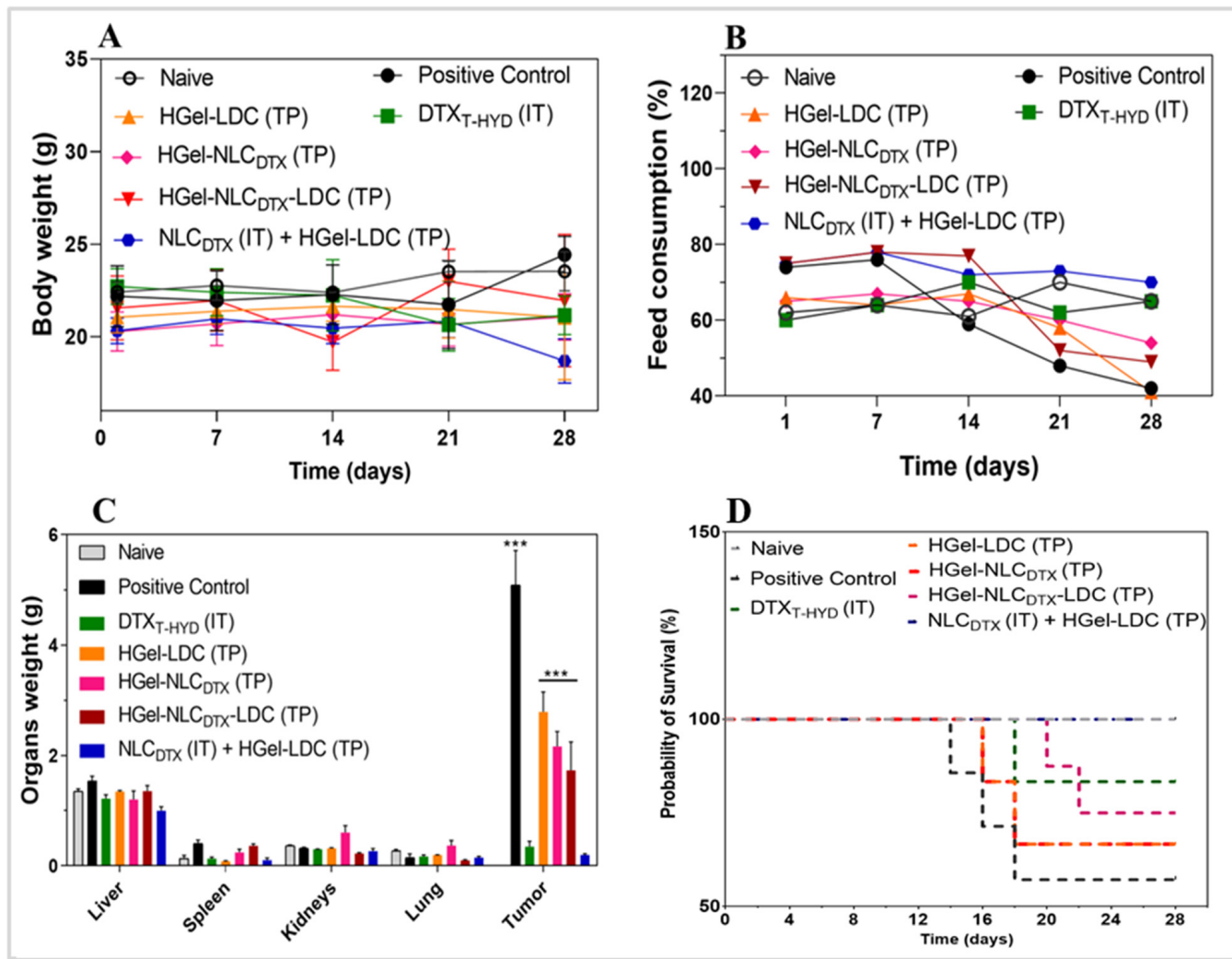

Figure 6. Evaluation of treatments and their adverse effects over C57BL/6J mice with melanoma. (A) Variation of body weight (B) Analysis of feed intake. (C) Weight of the organs (liver, spleen, kidneys, lung) and tumor region. (D) Kaplan-Meier survival curves for the different treated groups: naive, positive control (PBS group), positive control, DTX $\mathrm{T}_{\text {-HYD }}$ IT and nanohybrid hydrogel groups

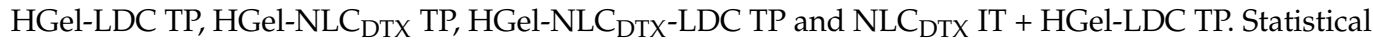
analysis: Two-Way ANOVA post-hoc Bonferroni, ${ }^{* * *} p<0.001 ; n=5$. 


\subsubsection{Macroscopic Parameters}

After 10 days of treatment, animals were euthanized, and the organs (liver, spleen, kidneys, lung and tumor area) were removed and weighed to assess possible anatomopathological macroscopic changes [83]. As shown in Figure 6C, no significant changes $(p<0.05)$ in the mass of liver, spleen, lung and kidney of the animals were observed, in comparison to the negative (healthy) control group. This means that no macroscopic evidence of hyperplasia, hepatomegaly and splenomegaly were detected. Also, the quantified mass of the tumor region was the highest in the animals from the positive control group and regressed in HGel-LDC TP, HGel-NLC DTX TP and HGel-NLC $_{\text {DTX-LDC TP groups, as }}$ shown in Figure 6C. The mass of the tumor region treated with the commercial formulation (DTX $\mathrm{D}_{\text {-HYD }}$ IT) and NLC $\mathrm{DTX}_{\mathrm{IT}}$ + HGel-LDC TP treatments were equivalent and significantly lower $(p<0.05)$ than that observed in other groups. These results corroborate those of the quantified tumor volume (Figure 4A, Table 4).

The survival rates of the animals were assessed by checking the time elapsed between the tumor induction and the exact time of the animal's death. In Figure 6D, it is possible to compare the cumulative animals' survival as a function of the duration of the experiment ( 28 days total). The positive control (tumor) group showed the worst survival rate $(40 \%$ or $2 / 5$ alive animals). At the end of the test, survival rates of $60 \%(3 / 5$ alive

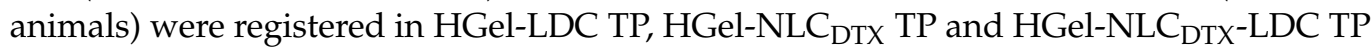
groups, of $80 \%$ (4/5 alive animals) in DTX $\mathrm{T}_{\mathrm{T}-\mathrm{HYD}}$ IT and of $100 \%$ in the treatment with

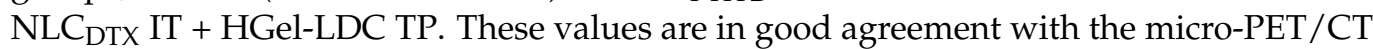
data (Table 4), i.e., groups with lower TLG values (better prognosis) also had the higher survival rates.

\subsection{Histopathology}

The murine B16 melanoma model is the most commonly metastatic melanoma model used in preclinical studies [84]. B16-F10 cell line was generated as the tenth serial passage subclone of the B16 parent tumor line in C57BL/6J mice. In general, the in vivo assays employing intradermal/subcutaneous implants of B16-F10 cells in C57BL/6J mice result in aggressively growing tumors [35]. Histopathological analysis of the tumor region and organs - spleen, liver, lung, kidney — of the animals treated with either DTX $\mathrm{T}_{\mathrm{T}-\mathrm{HYD}}$, HGel-

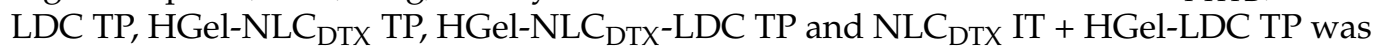
performed, as shown in Figure 7.

The degree of tumor tissue invasion was defined according to the Clark level scores, where: I: cancer is only in the epidermis; II: invasion to the papillary dermis; III: tumor fills the entire papillary dermis, without invading the reticular dermis; IV: invasion of the reticular dermis and V: invasion of the hypodermis [85]. The histological parameters that considered the tumor response to treatment were classified as: necrosis [86], reduction in the size of the neoplastic region [87], inflammatory infiltrate [88] and stromal fibroplasia [89].

It is known that the responses to therapy can be partial—when only part of the tumor regressed, or complete-when no more traces of the tumor are detected. Tumors that grow too fast can suffer spontaneous necrosis due to the hypoxia and nutrient (e.g., glucose) deficiency caused by scarce blood supplies [90]. This necrosis usually occurs at the center of the tumor, but in general it is not possible to distinguish between spontaneous and therapy-induced necrosis [90]. However, a therapy-induced necrosis is generally higher and more diffuse than spontaneous necrosis $[88,91]$, as observed herein. 


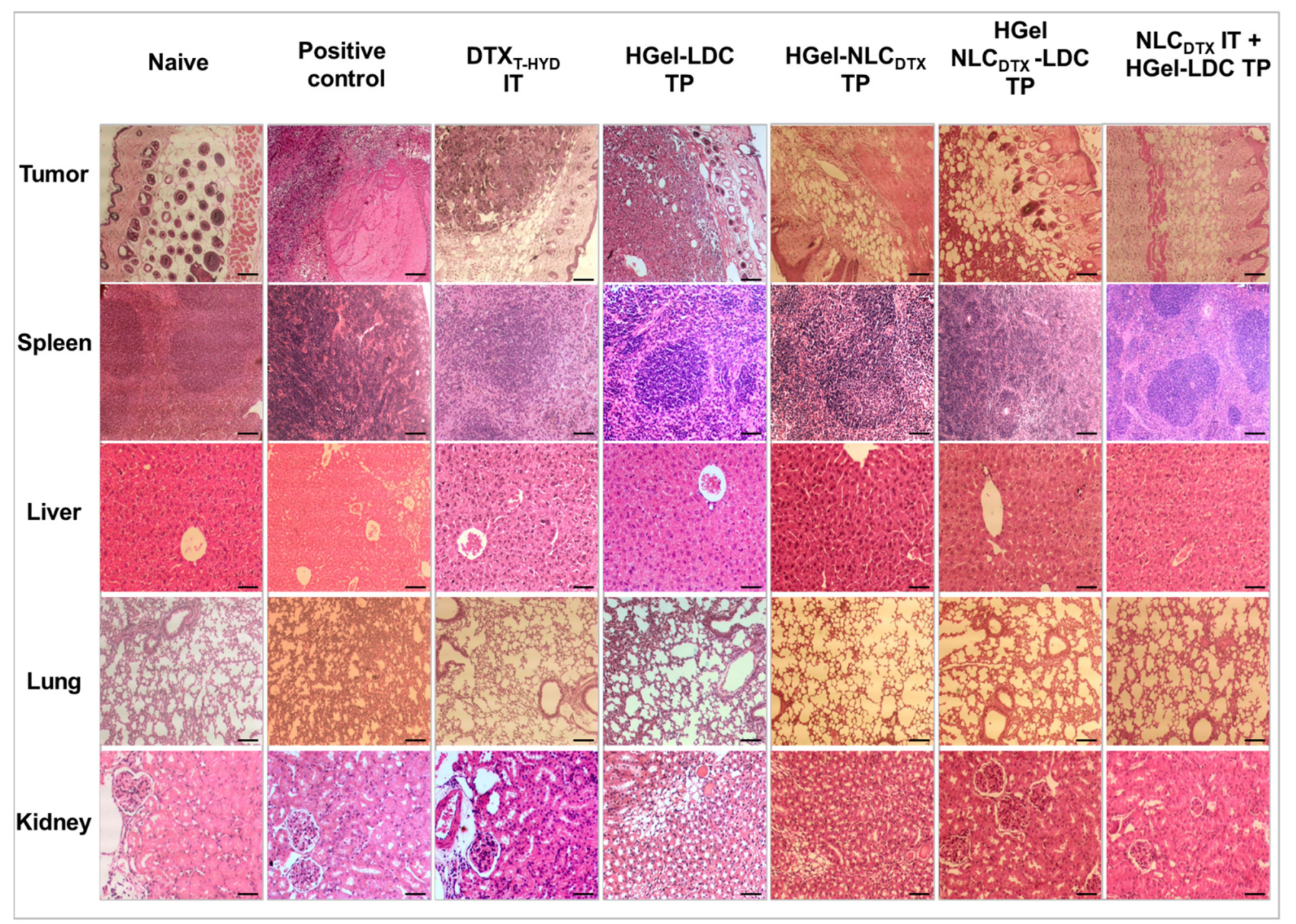

Figure 7. Histopathology sections of female C57BL/6J mice with orthotopically induced cancer (B16-F10 murine melanoma

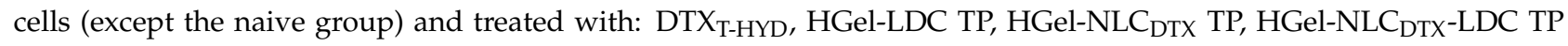
and NLC $_{\mathrm{DTX}}$ IT + Gel-LDC TP. Analysis of the tumor region, spleen, liver, lung, and kidney; H \& E, Scale bar $=50 \mu \mathrm{m}$, magnification: $100 \times$ or $400 \times$ ).

- Tumor

The Naive group didn't exhibit any tumor, so its image refers to normal skin, with well-defined epidermis, dermis, and hypodermis (left upper image of Figure 7). The melanocytes had evident cytoplasm, with some melanin located in the space between the keratinocytes of the basal layer and the epidermis, of usual histological aspects.

The positive control group had the worst prognosis, being classified as level $\mathrm{V}$ from the Clark score scale. In this group, the tissue region was thick, ulcerated and necrotic, with structural destruction of the epidermis. Blood vessels, typical of the angiogenesis were also observed. Histopathological findings show non equidistant melanocytic cells in the epidermis with different shapes and sizes (increased cytoplasm) and intense melanin production.

In the DTX $\mathrm{T}_{\mathrm{H}-\mathrm{H}}$ group both levels II and III Clark scores were present. Histopathological analysis revealed diffuse necrosis on tumor site, with punctual foci of non-equidistant melanocytic cells, in addition to stromal fibroplasia with moderate inflammatory infiltrate, that could be a sign of the effectiveness of the therapy.

The images from the NLC DTX IT + HGel-LDC TP group were classified as levels I and II in the Clark scores scale. This treatment provided the best histological prognosis. Histopathological analysis showed a punctual and limited focus of neoplastic melanocytic cells with intense (peri and intratumor) lymphocytic infiltration. The regions exhibited stromal fibroplasia and diffuse necrosis and apparently little affected epidermal surface. 
The slices from the HGel-LDC TP, HGel-NLC DTX $_{\text {TP }}$ and HGel-NLC DTX $_{\text {-LDC TP }}$ groups were classified at Clark's III and IV levels. These groups had diffuse tissue necrosis with foci of melanocytic cells and high melanin production. Histopathology revealed stromal fibroplasia with moderate inflammatory infiltrate, consisting of evident lymphocytes and melanophages (Figure 7).

- $\quad$ Organs (spleen, liver, lung and kidneys)

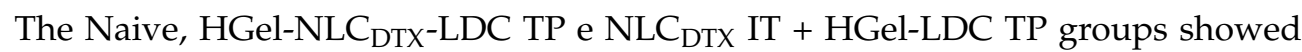
normal spleen histological structures, with the presence of splenic trabeculae, white and red pulps with usual aspects. The positive control group showed hyperplasia, splenic white pulp with proliferation of spindle cells of multinucleate aspects, intense inflammatory infiltrate, and metastasis. In the animals treated with DTX ${ }_{\text {T-HYD }}$ HGel-LDC TP and HGelNLC $_{\text {DTX }}$ TP, intense inflammatory infiltrate was observed (Figure 7).

Histological analyses of the liver revealed normal structures for the HGel-NLC $\mathrm{DTX}_{\mathrm{TP}}$, HGel-NLC DTX-LDC TP and NLC $_{\text {DTX }}$ IT + HGel-LDC TP batches. The findings revealed the presence of well-defined epithelial cells (hepatocytes), nucleated cells close to the sinusoidal cells (probably Kupffer cells or macrophages) with normal characteristics. The images from the positive control group exhibited mild neutrophilic periportal hepatitis, without necrosis and the presence of metastases. The slices from DTX T-HYD $_{\text {IT }}$ and HGel-LDC TP groups had evident inflammatory infiltrates (Figure 7). These analyses corroborate the observed changes in the hepatic markers ALT and AST (Table 5) for these groups.

In the histological evaluation of the lung, the naive group showed no abnormalities, with well-defined alveolar sacs, bronchi and bronchioles, usual macrophage or pneumocyte cells. The positive control group slices revealed moderate inflammatory infiltrate and pneumocyte hyperplasia, pulmonary edema with accumulation of protein fluid in the alveolar spaces and foci of pulmonary metastases. In the samples from the DTX $\mathrm{T}_{\mathrm{HYD}}$, HGel-LDC TP, HGel-NLC ${ }_{\text {DTX }}$ TP, HGel-NLC DTX-LDC TP e NLC $_{\text {DTX }}$ IT + Gel-LDC TP groups mild inflammatory infiltrate and pneumocyte hyperplasia were detected.

In all the evaluated treatments, the kidneys showed usual histological aspects with medullary and cortical regions containing peritubular capillaries, renal corpuscles, plus distal and proximal contorted tubules with well-defined cubic epithelium.

In summary, histopathological findings showed that the positive control group had hepatic, splenic and pulmonary lesions, with distal metastases in the lung, spleen and liver, plus an ulcerative and necrotizing primary tumor. The B16-F10 cell line has shown similar metastatic behavior to that of human melanoma, where metastases in bones, lungs, liver and spleen are observed [92].

For all the treated groups $\left(\mathrm{DTX}_{\mathrm{T}-\mathrm{HYD}}, \mathrm{HGel-LDC}\right.$ TP, HGel-NLC $\mathrm{DTX}_{\mathrm{TP}}$, HGel-NLC $\mathrm{DTX}^{-}$

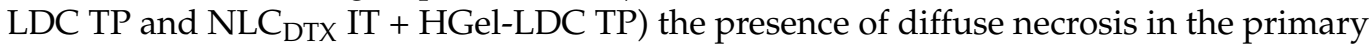
tumor, peri and intratumor inflammatory infiltrates and stromal fibroplasia suggest therapeutic efficacy. Furthermore, in these treatments, there was no evident melanocytic metastasis in the analyzed sections. None of the treatments resulted in complete eradication of the tumor, since neoplastic cells were observed in all groups. However, the therapy with DTX $_{\mathrm{T}-\mathrm{HYD}}$ and NLC $_{\mathrm{DTX}}$ IT + HGel-LDC TP had the smallest tumor area, with the best prognosis.

\section{Conclusions}

A hybrid hydrogel (HGel- NLC $\mathrm{DTX}_{\mathrm{DT}}$ ) with anesthetic and antineoplastic effects was developed. It was composed of docetaxel (0.5\%) loaded in nanostructured lipid carriers (NLC) plus a xanthan-chitosan polymeric matrix containing lidocaine (2\%). CryoEM analyses of hybrid hydrogel revealed preservation of the nanoparticles structure even after insertion into the biopolymer matrix. Such system also exhibited pseudoplastic properties, as desired for stable hydrogels. Cell viability tests showed that the cytotoxicity of free DTX was reduced after encapsulation in the hybrid formulation, as a result of sustained drug release. In vivo assays indicated that the hybrid hydrogel was able to inhibit the tumor growth in an equivalent manner to the conventional (free DTX) treatment. Moreover, the 
treatment with the hybrid hydrogel showed no adverse effects, as revealed by physical, biochemical and histopathological parameters. These results validate the proposal that docetaxel loaded by NLC associated with lidocaine-in-hydrogel can be an alternative and promising biocompatible formulation for the treatment of melanoma. The results also revealed interesting lidocaine (antitumor and analgesic) effects for the melanoma therapy.

Supplementary Materials: The following are available online at https: / www.mdpi.com/article / 10.3390/pharmaceutics13101552/s1, Table S1: Screening of the best concentrations of xanthan and chitosan biopolymers to be used as hydrogel excipients; Table S2. Rheological parameters ( $G^{\prime}$, $G^{\prime \prime}, G^{\prime} / G^{\prime \prime}$ and $\eta$ ) for the prepared hydrogel formulations, measured at $32.5^{\circ} \mathrm{C}$; Table S3. Values estimated by micro-PET/CT analysis of the percent ratio of the maximum and mean injected dose in tumor (\%ID TMax or\%ID TMean), adjacent tissue (\%ID BGMax or\%ID BGMean) and liver (\%ID LMax or\%ID LMean); Figure S1. Colloidal stability of formulations with DTX (NLC (NLCCTRL) during 12 months of storage at ambient temperature. (A) Size (nm) and PDI; B) Zeta potential (ZP); Figure S2. Digital photos of the hydrogels prepared with different chitosan:xanthan ratios (see Table S1). (A) control hydrogels, without NLC; (B) An example of LDC incorporated in chitosan:xanthan hydrogel; (C,D) Whitish hydrogels, after NLC incorporation. (D) Sample 2 (see text) showing the consistency of the prepared hybrid (NLC-in-hydrogel) formulation; Figure S3. CryoEM micrographs of nanostructured lipid carriers without (NLCCTRL) and with docetaxel (NLC DTX $_{\text {). }}$ 100.000x, 120 kV; Figure S4. Viability of NIH-3T3 (A), HaCaT (B), B16-F10 (C) and SK-MEL-103 (D) cells after $72 \mathrm{~h}$ of treatment with DTXT-HYD, LDC, NLC $\mathrm{DTX}_{1}, \mathrm{NLC}_{\mathrm{DTX}}+$ LDC, HGel-NLC $\mathrm{DTX}_{\mathrm{DTX}}$

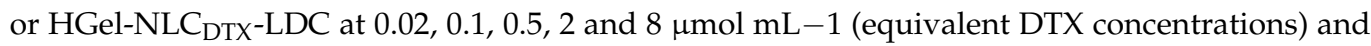
$0.03,0.1,0.6,2.5$ and $10 \mathrm{mmol} \mathrm{L}-1$ (equivalent LDC concentrations, evaluated by MTT assay. Data expressed as mean \pm standard error. Two-Way ANOVA post-hoc Bonferroni $\left(^{* * *} p<0.001\right.$ — $^{*}$ Treatment compared to control).; Figure S5. Tail-flick (analgesia) test. Maximum possible effect (MPE) as a function of time after treatment with hydrogels containing: 2\% lidocaine (HGel-LDC), control NLC - without docetaxel-plus 2\% lidocaine (HGel-NLCCTRL-LDC) or docetaxel in NLC plus $2 \%$ lidocaine (HGel-NLC DTX -LDC). For each formulation MPE significantly changed $(* * *<0.001)$ during the time course of the experiment (from 30 to $120 \mathrm{~min}$ ), but no significant differences were registered among the formulations at any experimental time analyzed; Figure S6. Digital images of C57BL/6J mice with melanoma after treatment with the hybrid formulation.

Author Contributions: Conceptualization, L.D.d.M.; Methodology, L.D.d.M. and L.N.M.R.; Investigation, L.D.d.M., L.N.M.R., F.V.d.C., G.H.R.d.S., P.C.L.F., S.Q.B., C.D.R., L.A.V. and D.R.d.A.; Formal analysis and Data curation, L.D.d.M., L.N.M.R. and E.d.P.; writing-original draft preparation, L.D.d.M.; writing-review and editing, L.D.d.M., L.N.M.R., G.H.R.d.S., D.R.d.A., S.Q.B. and E.d.P.; Visualization, L.N.M.R., D.R.d.A. and S.Q.B.; Supervision, Project administration, Resources and Funding acquisition, E.d.P. All authors have read and agreed to the published version of the manuscript.

Funding: This research was funded by the Brazilian agencies: FAPESP (grant \# 19/17784-0), CAPES and CNPq (L.D.M. and E.P. fellowships, respectively).

Institutional Review Board Statement: The study was conducted according to the guidelines of the University of Campinas-Institutional Animal Care and Use Committee (No 5345-1/19).

Informed Consent Statement: Not applicable.

Data Availability Statement: The data presented in this study are available on request from the corresponding author.

Acknowledgments: The authors are also grateful to the Brazilian Center for Research in Energy and Materials (CNPEM) for the access to CryoEM facility, to Cristália Prod. Quím. Farm. Ltda for providing docetaxel and lidocaine, to Blau Farm. S.A. for the donation of docetaxel trihydrate and to Cyclobras Ind. Com. Lab. Serv. Ltd.a, for kindly supplying 18F-fluorodeoxyglucose.

Conflicts of Interest: The authors declare no conflict of interest. 


\section{References}

1. Hong, A.M.; Waldstein, C.; Shivalingam, B.; Carlino, M.S.; Atkinson, V.; Kefford, R.F.; McArthur, G.A.; Menzies, A.M.; Thompson, J.F.; Long, G.V. Management of melanoma brain metastases: Evidence-based clinical practice guidelines by Cancer Council Australia. Eur. J. Cancer 2021, 142, 10-17. [CrossRef] [PubMed]

2. Urban, K.; Mehrmal, S.; Uppal, P.; Giesey, R.L.; Delost, G.R. The global burden of skin cancer: A longitudinal analysis from the Global Burden of Disease Study, 1990-2017. JAAD Int. 2021, 2, 98-108. [CrossRef] [PubMed]

3. Mishra, H.; Mishra, P.K.; Ekielski, A.; Jaggi, M.; Iqbal, Z.; Talegaonkar, S. Melanoma treatment: From conventional to nanotechnology. J. Cancer Res. Clin. Oncol. 2018, 144, 2283-2302. [CrossRef]

4. Rebecca, V.W.; Somasundaram, R.; Herlyn, M. Pre-clinical modeling of cutaneous melanoma. Nat. Commun. 2020, 11, 2858. [CrossRef] [PubMed]

5. Sharma, G.; Parchur, A.K.; Jagtap, J.M.; Hansen, C.P.; Joshi, A. Hybrid Nanostructures in Targeted Drug Delivery. In Hybrid Nanostructures for Cancer Theranostics; Elsevier Inc.: Amsterdam, The Netherlands, 2019; pp. 139-158.

6. Müller, R.H.; Radtke, M.; Wissing, S.A. Solid lipid nanoparticles (SLN) and nanostructured lipid carriers (NLC) in cosmetic and dermatological preparations. Adv. Drug Deliv. Rev. 2002, 54, 131-155. [CrossRef]

7. Kovačević, A.B.; Müller, R.H.; Keck, C.M. Formulation development of lipid nanoparticles: Improved lipid screening and development of tacrolimus loaded nanostructured lipid carriers (NLC). Int. J. Pharm. 2020, 576, 118918. [CrossRef] [PubMed]

8. Garcês, A.; Amaral, M.H.; Sousa Lobo, J.M.; Silva, A.C. Formulations based on solid lipid nanoparticles (SLN) and nanostructured lipid carriers (NLC) for cutaneous use: A review. Eur. J. Pharm. Sci. 2018, 112, 159-167. [CrossRef]

9. Souto, E.B.; Wissing, S.; Barbosa, C.; Müller, R.H. Development of a controlled release formulation based on SLN and NLC for topical clotrimazole delivery. Int. J. Pharm. 2004, 278, 71-77. [CrossRef]

10. Kharkar, P.B.; Talkar, S.S.; Patravale, V.B. An industrially viable technique for fabrication of docetaxel NLCs for oncotherapy. Int. J. Pharm. 2020, 577, 119082. [CrossRef]

11. Da Rocha, M.C.O.; Da Silva, P.B.; Radicchi, M.A.; Andrade, B.Y.G.; De Oliveira, J.V.; Venus, T.; Merker, C.; Estrela-Lopis, I.; Longo, J.P.F.; Báo, S.N. Docetaxel-loaded solid lipid nanoparticles prevent tumor growth and lung metastasis of $4 \mathrm{~T} 1$ murine mammary carcinoma cells. J. Nanobiotechnol. 2020, 18, 43. [CrossRef]

12. Sheikhpour, M.; Barani, L.; Kasaeian, A. Biomimetics in drug delivery systems: A critical review. J. Control. Release 2017, 253, 97-109. [CrossRef]

13. Martínez-Ruvalcaba, A.; Chornet, E.; Rodrigue, D. Viscoelastic properties of dispersed chitosan/xanthan hydrogels. Carbohydr. Polym. 2007, 67, 586-595. [CrossRef]

14. Li, J.; Mooney, D.J. Designing hydrogels for controlled drug delivery. Nat. Rev. Mater. 2016, 1, 16071. [CrossRef] [PubMed]

15. Matarazzo, A.P.; Elisei, L.M.S.; Carvalho, F.C.; Bonfílio, R.; Ruela, A.L.M.; Galdino, G.; Pereira, G.R. Mucoadhesive nanostructured lipid carriers as a cannabidiol nasal delivery system for the treatment of neuropathic pain. Eur. J. Pharm. Sci. 2021, 159, 105698. [CrossRef] [PubMed]

16. Ribeiro, L.N.M.; Franz-Montan, M.; Breitkreitz, M.C.; Rodrigues da Silva, G.H.; Castro, S.R.; Guilherme, V.A.; de Araújo, D.R.; de Paula, E. Nanohybrid hydrogels designed for transbuccal anesthesia. Int. J. Nanomed. 2018, 13, 6453-6463. [CrossRef] [PubMed]

17. Rajinikanth, P.S.; Chellian, J. Development and evaluation of nanostructured lipid carrier-based hydrogel for topical delivery of 5-fluorouracil. Int. J. Nanomed. 2016, 11, 5067-5077. [CrossRef]

18. Muniz, B.V.; Baratelli, D.; Di Carla, S.; Serpe, L.; da Silva, C.B.; Guilherme, V.A.; Ribeiro, L.N.M.; Cereda, C.M.S.; de Paula, E.; Volpato, M.C.; et al. Hybrid Hydrogel Composed of Polymeric Nanocapsules Co-Loading Lidocaine and Prilocaine for Topical Intraoral Anesthesia. Sci. Rep. 2018, 8, 17972. [CrossRef] [PubMed]

19. Kang, D.; Zhao, L.; Wang, H. Cytotoxic effects of local anesthesia through lidocaine/ropivacaine on human melanoma cell lines. Braz. J. Anesthesiol. 2016, 66, 594-602. [CrossRef]

20. Yang, X.; Zhao, L.; Li, M.; Yan, L.; Zhang, S.; Mi, Z.; Ren, L.; Xu, J. Lidocaine enhances the effects of chemotherapeutic drugs against bladder cancer. Sci. Rep. 2018, 8, 598. [CrossRef]

21. Geronimo, G.; Rodrigues da Silva, G.H.; Moura, L.D.; Ribeiro, L.N.M.; Guilherme, V.A.; Mendonça, T.C.; Castro, S.R.; Breitkreitz, M.C.; de Paula, E. Development of $S$ 75: $R 25$ bupivacaine-loaded lipid nanoparticles functionalized with essential oils for treating melanoma. J. Chem. Technol. Biotechnol. 2021, 96, 2197-2207. [CrossRef]

22. Frames, W.L.; Zuckerman, L.M.; Mirshahidi, H.R.; Williams, N.L.; Shields, T.G.; Otoukesh, S.; Mirshahidi, S. Antiproliferative effect of bupivacaine on patient-derived sarcoma cells. Mol. Clin. Oncol. 2020, 13, 1. [CrossRef] [PubMed]

23. Gu, J.H.; Liu, C.C.; Xie, J.L.; Ma, B.; Cui, S.M.; Yang, G.Z.; He, S.C. The Local Anesthetic Bupivacaine Inhibits the Progression of Non-Small Cell Lung Cancer by Inducing Autophagy Through Akt/mTOR Signaling. Front. Oncol. 2021, 11, 170. [CrossRef] [PubMed]

24. Xuan, W.; Zhao, H.; Hankin, J.; Chen, L.; Yao, S.; Ma, D. Local anesthetic bupivacaine induced ovarian and prostate cancer apoptotic cell death and underlying mechanisms in vitro. Sci. Rep. 2016, 6, 26277. [CrossRef]

25. Wang, W.; Li, T. Ropivacaine inhibits the proliferation and migration of colorectal cancer cells through ITGB1. Bioengineered 2021, 12, 44-53. [CrossRef]

26. Zhou, D.; Wang, L.; Cui, Q.; Iftikhar, R.; Xia, Y.; Xu, P. Repositioning Lidocaine as an Anticancer Drug: The Role Beyond Anesthesia. Front. Cell Dev. Biol. 2020, 8, 565. [CrossRef] 
27. Mirshahidi, S.; Shields, T.; de Necochea-Campion, R.; Yuan, X.; Janjua, A.; Williams, N.; Mirshahidi, H.; Reeves, M.; DuerksenHughes, P.; Zuckerman, L.S. Bupivacaine and Lidocaine Induce Apoptosis in Osteosarcoma Tumor Cells. Clin. Orthop. Relat. Res. 2021, 479, 180-194. [CrossRef]

28. Ye, L.; Zhang, Y.; Chen, Y.J.; Liu, Q. Anti-tumor effects of lidocaine on human gastric cancer cells in vitro. Bratisl. Med. J. 2019, 120, 212-217. [CrossRef] [PubMed]

29. Viderman, D.; Nurpeissov, A.; Bilotta, F. Intravenous lidocaine in the management of severe brain tumor-associated headache. J. Clin. Anesth. 2019, 55, 67-68. [CrossRef] [PubMed]

30. Ribeiro, L.N.M.; Franz-Montan, M.; Breitkreitz, M.C.; Alcântara, A.C.S.; Castro, S.R.; Guilherme, V.A.; Barbosa, R.M.; de Paula, E. Nanostructured lipid carriers as robust systems for topical lidocaine-prilocaine release in dentistry. Eur. J. Pharm. Sci. 2016, 93, 192-202. [CrossRef]

31. Rodrigues da Silva, G.H.; Geronimo, G.; Ribeiro, L.N.M.; Guilherme, V.A.; de Moura, L.D.; Bombeiro, A.L.; Oliveira, J.D.; Breitkreitz, M.C.; de Paula, E. Injectable in situ forming nanogel: A hybrid Alginate-NLC formulation extends bupivacaine anesthetic effect. Mater. Sci. Eng. C 2020, 109, 110608. [CrossRef]

32. Nahak, P.; Karmakar, G.; Roy, B.; Guha, P.; Sapkota, M.; Koirala, S.; Chang, C.-H.; Panda, A.K. Physicochemical studies on local anaesthetic loaded second generation nanolipid carriers. RSC Adv. 2015, 5, 26061-26070. [CrossRef]

33. Riss, T.; Niles, A.; Moravec, R.; Karassina, N.; Vidugiriene, J. Cytotoxicity Assays: In Vitro Methods to Measure Dead Cells; Eli Lilly \& Company and the National Center for Advancing Translational Sciences: Bethesda, MD, USA, 2004.

34. Shin, S.; Cho, C.; Yang, H. Development of lidocaine gels for enhanced local anesthetic action. Int. J. Pharm. 2004, 287, 73-78. [CrossRef] [PubMed]

35. Nakamura, K.; Yoshikawa, N.; Yamaguchi, Y.; Kagota, S.; Shinozuka, K.; Kunitomo, M. Characterization of mouse melanoma cell lines by their mortal malignancy using an experimental metastatic model. Life Sci. 2002, 70, 791-798. [CrossRef]

36. Wang, L.; Liu, Z.; Liu, D.; Liu, C.; Juan, Z.; Zhang, N. Docetaxel-loaded-lipid-based-nanosuspensions (DTX-LNS): Preparation, pharmacokinetics, tissue distribution and antitumor activity. Int. J. Pharm. 2011, 413, 194-201. [CrossRef] [PubMed]

37. Patel, N.R.; Piroyan, A.; Ganta, S.; Morse, A.B.; Candiloro, K.M.; Solon, A.L.; Nack, A.H.; Galati, C.A.; Bora, C.; Maglaty, M.A.; et al. In Vitro and In Vivo evaluation of a novel folate-targeted theranostic nanoemulsion of docetaxel for imaging and improved anticancer activity against ovarian cancers. Cancer Biol. Ther. 2018, 19, 554-564. [CrossRef]

38. Estebe, J.P. Intravenous lidocaine. Best Pract. Res. Clin. Anaesthesiol. 2017, 31, 513-521. [CrossRef] [PubMed]

39. Dagher, F.B.; Yared, G.M.; Machtou, P. An evaluation of $2 \%$ lidocaine with different concentrations of epinephrine for inferior alveolar nerve block. J. Endod. 1997, 23, 178-180. [CrossRef]

40. Santos, M.S.C.; Gouvêa, A.L.; de Moura, L.D.; Paterno, L.G.; de Souza, P.E.N.; Bastos, A.P.; Damasceno, E.A.M.; Veiga-Souza, F.H.; de Azevedo, R.B.; Báo, S.N. Nanographene oxide-methylene blue as phototherapies platform for breast tumor ablation and metastasis prevention in a syngeneic orthotopic murine model. J. Nanobiotechnol. 2018, 16, 9. [CrossRef]

41. Bland, J.M.; Altman, D.G. Survival probabilities (the Kaplan-Meier method). BMJ 1998, 317, 1572. [CrossRef]

42. Jiang, S.; Zhang, L.-F.; Zhang, H.-W.; Hu, S.; Lu, M.-H.; Liang, S.; Li, B.; Li, Y.; Li, D.; Wang, E.-D.; et al. A novel miR-155/miR-143 cascade controls glycolysis by regulating hexokinase 2 in breast cancer cells. EMBO J. 2012, 31, 1985-1998. [CrossRef]

43. Takahashi, M.E.S.; Mosci, C.; Souza, E.M.; Brunetto, S.Q.; Etchebehere, E.; Santos, A.O.; Camacho, M.R.; Miranda, E.; Lima, M.C.L.; Amorim, B.J.; et al. Proposal for a Quantitative 18F-FDG PET/CT Metabolic Parameter to Assess the Intensity of Bone Involvement in Multiple Myeloma. Sci. Rep. 2019, 9, 16429. [CrossRef] [PubMed]

44. Albano, J.M.R.; de Morais Ribeiro, L.N.; Couto, V.M.; Messias, M.B.; Rodrigues da Silva, G.H.; Breitkreitz, M.C.; de Paula, E.; Pickholz, M. Rational design of polymer-lipid nanoparticles for docetaxel delivery. Colloids Surf. B Biointerfaces 2019, $175,56-64$. [CrossRef] [PubMed]

45. Guilherme, V.A.; Ribeiro, L.N.M.; Alcântara, A.C.S.; Castro, S.R.; Rodrigues da Silva, G.H.; da Silva, C.G.; Breitkreitz, M.C.; Clemente-Napimoga, J.; Macedo, C.G.; Abdalla, H.B.; et al. Improved efficacy of naproxen-loaded NLC for temporomandibular joint administration. Sci. Rep. 2019, 9, 11160. [CrossRef] [PubMed]

46. Rodrigues da Silva, G.H.; Geronimo, G.; García-López, J.P.; Ribeiro, L.N.M.; de Moura, L.D.; Breitkreitz, M.C.; Feijóo, C.G.; de Paula, E. Articaine in functional NLC show improved anesthesia and anti-inflammatory activity in zebrafish. Sci. Rep. 2020, 10, 19733. [CrossRef]

47. Pleguezuelos-Villa, M.; Nácher, A.; Hernández, M.J.; Busó, M.A.O.V.; Barrachina, M.; Peñalver, N.; Díez-Sales, O. A novel lidocaine hydrochloride mucoadhesive films for periodontal diseases. J. Mater. Sci. Mater. Med. 2019, 30, 14. [CrossRef]

48. Yaşayan, G.; Karaca, G.; Akgüner, Z.P.; Bal Öztürk, A. Chitosan/collagen composite films as wound dressings encapsulating allantoin and lidocaine hydrochloride. Int. J. Polym. Mater. Polym. Biomater. 2020, 70, 623-635. [CrossRef]

49. Vigato, A.A.; Querobino, S.M.; de Faria, N.C.; Candido, A.C.B.B.; Magalhães, L.G.; Cereda, C.M.S.; Tófoli, G.R.; Campos, E.V.R.; Machado, I.P.; Fraceto, L.F.; et al. Physico-Chemical Characterization and Biopharmaceutical Evaluation of Lipid-Poloxamer-Based Organogels for Curcumin Skin Delivery. Front. Pharmacol. 2019, 10, 1006. [CrossRef] [PubMed]

50. Vigato, A.A.; Querobino, S.M.; de Faria, N.C.; de Freitas, A.C.P.; Leonardi, G.R.; de Paula, E.; Cereda, C.M.S.; Tófoli, G.R.; de Araujo, D.R. Synthesis and characterization of nanostructured lipid-poloxamer organogels for enhanced skin local anesthesia. Eur. J. Pharm. Sci. 2019, 128, 270-278. [CrossRef]

51. Ćirić, A.; Medarević, Đ.; Čalija, B.; Dobričić, V.; Mitrić, M.; Djekic, L. Study of chitosan/xanthan gum polyelectrolyte complexes formation, solid state and influence on ibuprofen release kinetics. Int. J. Biol. Macromol. 2020, 148, 942-955. [CrossRef] [PubMed] 
52. Muri, H.; Hoang, L.; Hjelme, D. Mapping Nanoparticles in Hydrogels: A Comparison of Preparation Methods for Electron Microscopy. Appl. Sci. 2018, 8, 2446. [CrossRef]

53. Jores, K.; Mehnert, W.; Drechsler, M.; Bunjes, H.; Johann, C.; Mäder, K. Investigations on the structure of solid lipid nanoparticles (SLN) and oil-loaded solid lipid nanoparticles by photon correlation spectroscopy, field-flow fractionation and transmission electron microscopy. J. Control. Release 2004, 95, 217-227. [CrossRef]

54. Rodrigues da Silva, G.H.; Lemes, J.B.P.; Geronimo, G.; Lima, F.F.; Moura, L.D.; Santos, A.C.; Carvalho, N.S.; Malange, K.F.; Breitkreitz, M.C.; Parada, C.A.; et al. Lipid nanoparticles loaded with butamben and designed to improve anesthesia at inflamed tissues. Biomater. Sci. 2021, 9, 3378-3389. [CrossRef]

55. Che, C.L.; Zhang, Y.M.; Zhang, H.H.; Sang, Y.L.; Lu, B.; Dong, F.-S.; Zhang, L.-J.; Lv, F.-Z. DNA microarray reveals different pathways responding to paclitaxel and docetaxel in non-small cell lung cancer cell line. Int. J. Clin. Exp. Pathol. 2013, 6, 1538.

56. Attia, R.; Tolba, M.; Trivedi, R.; Tadros, M.; Arafa, H.; Abdel-Naim, A. The chemomodulatory effects of glufosfamide on docetaxel cytotoxicity in prostate cancer cells. PeerJ 2016, 4, e2168. [CrossRef] [PubMed]

57. Liu, D.; Liu, Z.; Wang, L.; Zhang, C.; Zhang, N. Nanostructured lipid carriers as novel carrier for parenteral delivery of docetaxel. Colloids Surf. B Biointerfaces 2011, 85, 262-269. [CrossRef] [PubMed]

58. Vohra, T.; Kaur, I.; Heer, H.; Rayasa, R.M. Nanolipid carrier-based thermoreversible gel for localized delivery of docetaxel to breast cancer. Cancer Nanotechnol. 2013, 4, 1-12. [CrossRef] [PubMed]

59. Karniel, M.; Beitner, R. Local Anesthetics Induce a Decrease in the Levels of Glucose 1,6-Bisphosphate, Fructose 1,6-Bisphosphate, and ATP, and in the Viability of Melanoma Cells. Mol. Genet. Metab. 2000, 69, 40-45. [CrossRef]

60. Desai, S.P.; Kojima, K.; Vacanti, C.A.; Kodama, S. Lidocaine inhibits NIH-3T3 cell multiplication by increasing the expression of cyclin-dependent kinase inhibitor 1A (p21). Anesth. Analg. 2008, 107, 1592-1597. [CrossRef]

61. Rafehi, H.; Orlowski, C.; Georgiadis, G.T.; Ververis, K.; El-Osta, A.; Karagiannis, T.C. Clonogenic assay: Adherent cells. J. Vis. Exp. 2011, 49, e2573. [CrossRef]

62. Choi, Y.J.; Park, J.H.; Han, J.W.; Kim, E.; Jae-Wook, O.; Lee, S.Y.; Kim, J.H.; Gurunathan, S. Differential cytotoxic potential of silver nanoparticles in human ovarian cancer cells and ovarian cancer stem cells. Int. J. Mol. Sci. 2016, 17, 2077. [CrossRef] [PubMed]

63. Peira, E.; Chirio, D.; Battaglia, L.; Barge, A.; Chegaev, K.; Gigliotti, C.L.; Ferrara, B.; Dianzani, C.; Gallarate, M.; Luca Gigliotti, C. Micro and Nano Carriers Solid lipid nanoparticles carrying lipophilic derivatives of doxorubicin: Preparation, characterization, and in vitro cytotoxicity studies Solid lipid nanoparticles carrying lipophilic derivatives of doxorubicin: Preparation, characterization, and in vitro cytotoxicity studies. J. Microencapsul. 2016, 33, 381-390. [CrossRef]

64. Bannon, A.W.; Malmberg, A.B. Models of Nociception: Hot-Plate, Tail-Flick, and Formalin Tests in Rodents. Curr. Protoc. Neurosci. 2007. [CrossRef] [PubMed]

65. Atabaki, R.; Hassanpour-Ezatti, M. Improvement of Lidocaine Local Anesthetic Action Using Lallemantia royleana Seed Mucilage as an Excipient. Iran. J. Pharm. Res. 2014, 13, 1431-1436. [PubMed]

66. Cheung, R.C.F.; Ng, T.B.; Wong, J.H.; Chan, W.Y. Chitosan: An Update on Potential Biomedical and Pharmaceutical Applications. Mar. Drugs 2015, 13, 5156-5186. [CrossRef]

67. Chellat, F.; Tabrizian, M.; Dumitriu, S.; Chornet, E.; Magny, P.; Rivard, C.-H.; Yahia, H. In vitro and in vivo biocompatibility of chitosan-xanthan polyionic complex. J. Biomed. Mater. Res. 2000, 51, 107-116. [CrossRef]

68. Chamaraux-Tran, T.N.; Mathelin, C.; Aprahamian, M.; Joshi, G.P.; Tomasetto, C.; Diemunsch, P.; Akladios, C. Antitumor effects of lidocaine on human breast cancer cells: An in vitro and in vivo experimental trial. Anticancer Res. 2018, 38, 95-105. [CrossRef]

69. Raff, A.B.; Thomas, C.N.; Chuang, G.S.; Avram, M.M.; Le, M.H.; Anderson, R.R.; Purschke, M. Lidocaine-induced potentiation of thermal damage in skin and carcinoma cells. Lasers Surg. Med. 2019, 51, 88-94. [CrossRef]

70. Long, J.; Etxeberria, A.E.; Nand, A.V.; Bunt, C.R.; Ray, S.; Seyfoddin, A. A 3D printed chitosan-pectin hydrogel wound dressing for lidocaine hydrochloride delivery. Mater. Sci. Eng. C. 2019, 104, 109873. [CrossRef]

71. Ten Tije, A.J.; Verweij, J.; Loos, W.J.; Sparreboom, A. Pharmacological effects of formulation vehicles: Implications for cancer chemotherapy. Clin. Pharmacokinet. 2003, 42, 665-685. [CrossRef]

72. Fang, J.Y.; Hung, C.F.; Hwang, T.L.; Huang, Y.L. Physicochemical characteristics and in vivo deposition of liposome-encapsulated tea catechins by topical and intratumor administrations. J. Drug Target. 2005, 13, 19-27. [CrossRef] [PubMed]

73. Hong, W.X.; Haebe, S.; Lee, A.S.; Benedikt Westphalen, C.; Norton, J.A.; Jiang, W.; Levy, R. Intratumoral immunotherapy for early-stage solid tumors. Clin. Cancer Res. 2020, 26, 3091-3099. [CrossRef] [PubMed]

74. Lee, J.R.; Shin, J.H.; Park, J.H.; Song, S.U.; Choi, G.S. Combined treatment with intratumoral injection of dendritic cells and topical application of imiquimod for murine melanoma. Clin. Exp. Dermatol. 2007, 32, 541-549. [CrossRef] [PubMed]

75. Liang, H.; Yang, Y.; Yang, K.; Wu, Y.; Boone, J.M.; Cherry, S.R. A microPET/CT system for in vivo small animal imaging. Phys. Med. Biol. 2007, 52, 3881. [CrossRef] [PubMed]

76. Ramos, C.; Erdi, Y.; Gonen, M.; Riedel, E.; Yeung, H.; Macapinlac, H.; Chisin, R.; Larson, S. FDG-PET standardized uptake values in normal anatomical structures using iterative reconstruction segmented attenuation correction and filtered back-projection. Eur. J. Nucl. Med. 2001, 28, 155-164. [CrossRef]

77. Li, Y.; Zschaeck, S.; Lin, Q.; Chen, S.; Chen, L.; Wu, H. Metabolic parameters of sequential 18F-FDG PET/CT predict overall survival of esophageal cancer patients treated with (chemo-) radiation. Radiat. Oncol. 2019, 14, 35. [CrossRef] 
78. Tseng, J.R.; Kang, K.W.; Dandekar, M.; Yaghoubi, S.; Lee, J.H.; Christensen, J.G.; Muir, S.; Vincent, P.W.; Michaud, N.R.; Gambhir, S.S. Preclinical Efficacy of the c-Met Inhibitor CE-355621 in a U87 MG Mouse Xenograft Model Evaluated by 18F-FDG Small-Animal PET. J. Nucl. Med. 2008, 49, 129-134. [CrossRef] [PubMed]

79. Bhakuni, G.S.; Bedi, O.; Bariwal, J.; Deshmukh, R.; Kumar, P. Animal models of hepatotoxicity. Inflamm. Res. 2015, 65, 13-24. [CrossRef] [PubMed]

80. Vaidya, V.S.; Ferguson, M.A.; Bonventre, J.V. Biomarkers of Acute Kidney Injury. Annu. Rev. Pharmacol. Toxicol. 2008, $48,463$. [CrossRef] [PubMed]

81. Kellum, J.A.; Romagnani, P.; Ashuntantang, G.; Ronco, C.; Zarbock, A.; Anders, H.-J. Acute kidney injury. Nat. Rev. Dis. Prim. 2021, 7, 52. [CrossRef] [PubMed]

82. Zhou, X.; Hansson, G.K. Effect of Sex and Age on Serum Biochemical Reference Ranges in C57BL/6J Mice. Comp. Med. 2004, 54, 176-178. [PubMed]

83. Schadendorf, D.; van Akkooi, A.C.J.; Berking, C.; Griewank, K.G.; Gutzmer, R.; Hauschild, A.; Stang, A.; Roesch, A.; Ugurel, S. Melanoma. Lancet 2018, 392, 971-984. [CrossRef]

84. Saleh, J. Murine models of melanoma. Pathol. -Res. Pract. 2018, 214, 1235-1238. [CrossRef]

85. Definition of Clark Level V Skin Cancer-NCI. Dictionary of Cancer Terms-National Cancer Institute. Available online: https:/ /www. cancer.gov/publications/dictionaries/cancer-terms/def/clark-level-v-skin-cancer (accessed on 30 April 2021).

86. Verma, N.; Cowperthwaite, M.C.; Burnett, M.G.; Markey, M.K. Differentiating tumor recurrence from treatment necrosis: A review of neuro-oncologic imaging strategies. Neuro-Oncology 2013, 15, 515-534. [CrossRef] [PubMed]

87. Carlsson, G.; Gullberg, B.; Hafström, L. Estimation of liver tumor volume using different formulas-An experimental study in rats. J. Cancer Res. Clin. Oncol. 1983, 105, 20-23. [CrossRef] [PubMed]

88. Ladstein, R.G.; Bachmann, I.M.; Straume, O.; Akslen, L.A. Tumor Necrosis Is a Prognostic Factor in Thick Cutaneous Melanoma. Am. J. Surg. Pathol. 2012, 36, 1477-1482. [CrossRef] [PubMed]

89. Ruiter, D.; Bogenrieder, T.; Elder, D.; Herlyn, M. Melanoma-stroma interactions: Structural and functional aspects. Lancet Oncol. 2002, 3, 35-43. [CrossRef]

90. Lee, S.Y.; Ju, M.K.; Jeon, H.M.; Jeong, E.K.; Lee, Y.J.; Kim, C.H.; Park, H.G.; Han, S.I.; Kang, H.S. Regulation of Tumor Progression by Programmed Necrosis. Oxid. Med. Cell. Longev. 2018, 28. [CrossRef]

91. Vakkila, J.; Lotze, M.T. Inflammation and necrosis promote tumour growth. Nat. Rev. Immunol. 2004, 4, 641-648. [CrossRef]

92. Winkelmann, C.T.; Daibes Figueroa, S.; Rold, T.L.; Volkert, W.A.; Hoffman, T.J. Microimaging Characterization of a B16-F10 Melanoma Metastasis Mouse Model. Mol. Imaging 2006, 5, 105-114. [CrossRef] 